University of Nebraska - Lincoln

DigitalCommons@University of Nebraska - Lincoln Theses, Student Research, and Creative Activity: Department of Teaching, Learning and Teacher
Department of Teaching, Learning and Teacher

Education

6-2011

\title{
Extensiveness and Perceptions of Lecture Demonstrations in the High School Chemistry Classroom
}

Daniel S. Price

University of Nebraska-Lincoln, dprice@jeffco.k12.co.us

Follow this and additional works at: https://digitalcommons.unl.edu/teachlearnstudent

Part of the Science and Mathematics Education Commons, and the Secondary Education and Teaching Commons

Price, Daniel S., "Extensiveness and Perceptions of Lecture Demonstrations in the High School Chemistry Classroom" (2011). Theses, Student Research, and Creative Activity: Department of Teaching, Learning and Teacher Education. 12.

https://digitalcommons.unl.edu/teachlearnstudent/12

This Article is brought to you for free and open access by the Department of Teaching, Learning and Teacher Education at DigitalCommons@University of Nebraska - Lincoln. It has been accepted for inclusion in Theses, Student Research, and Creative Activity: Department of Teaching, Learning and Teacher Education by an authorized administrator of DigitalCommons@University of Nebraska - Lincoln. 


\title{
EXTENSIVENESS AND PERCEPTIONS OF LECTURE DEMONSTRATIONS IN THE HIGH SCHOOL CHEMISTRY CLASSROOM
}

by

\author{
Daniel S. Price
}

A Dissertation

Presented to the Faculty of

The Graduate College at the University of Nebraska In Partial Fulfillment of Requirements

For the Degree of Doctor of Philosophy

Major: Interdepartmental Area of Educational Studies

Under the Supervision of Professor David W. Brooks

Lincoln, Nebraska

June 2011 


\title{
EXTENSIVENESS AND PERCEPTIONS OF LECTURE DEMONSTRATIONS IN THE HIGH SCHOOL CHEMISTRY CLASSROOM
}

\author{
Daniel Scott Price, Ph.D. \\ University of Nebraska, 2011
}

Adviser: David W. Brooks

While lecture demonstrations have been conducted in chemistry classrooms for hundreds of years, little research exists to document the frequency with which such demonstrations are employed or their effect on learners' motivation and performance. A mixed-methods research study was performed, using quantitative and qualitative survey data, along with qualitative data from follow-up interviews and structured correspondence, to determine the extent to which lecture demonstrations are used in high school chemistry instruction, and the perceived effects of viewing such demonstrations on students' performance on course assignments and on motivation to excel in current and future chemistry courses. Fifty-two randomly selected chemistry teachers completed a survey regarding their present and projected use of classroom demonstration. Twelve of the survey participants provided elaboration in the form of an extended questionnaire. Data indicate that all except one of the survey participants currently employ lecture demonstrations, and all anticipate performing the same amount of, or more, demonstrations in their future instruction. Extended questionnaire and survey data reveal that the participating chemistry teachers perceive substantial positive effects on students' performance on classroom assignments and a lesser, though still positive, effect, on learners' motivation. No correlations were observed between the number of lecture demonstrations performed and educators' years of experience teaching chemistry, previous exposure to demonstrations, or undergraduate degrees earned. 
copyright (C) 2011 Daniel S. Price 


\section{Dedications}

The author would like to thank the following, each equally responsible for the existence of this project:

Mentor Dr. David W. Brooks, who took on yet another doctoral student with big ideas and no sense of direction and coached him through the training to the start of the marathon;

Beloved bride Kelly, who as long as I have known her has responded "have you ever tried?" whenever I have suggested that something might be beyond my ability;

Daughters Katie and Gabi, who flourish despite the expectations of so many who doubted that they could survive, and remind us every day that what we are doing is not the hardest thing we have ever done;

Parents William J. and Katherine M. Price, who did not live to see this day but always believed that it would come to be. 


\section{Table of Contents}

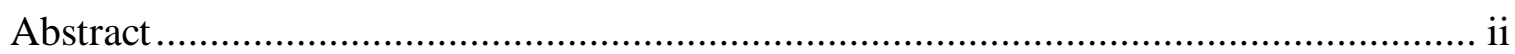

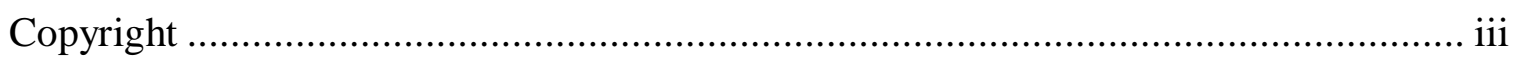

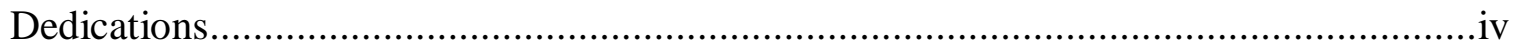

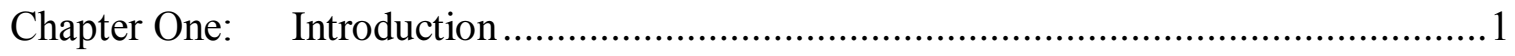

Context of the Study ....................................................... 1

Definition of Lecture Demonstration........................................ 1

Purpose of the Study .......................................................... 3

Primary Research Questions ............................................4

Minor Research Question.......................................................5

Significance of the Study ..................................................

Chapter Two: Review of Literature ............................................................

Introduction ..................................................................

Justifications for use of demonstrations .................................... 7

Increased student motivation............................................. 9

Increased student learning .............................................. 11

Substitutes for laboratory experiences ................................... 14

Summary of, and deficiencies in, literature ............................ 14

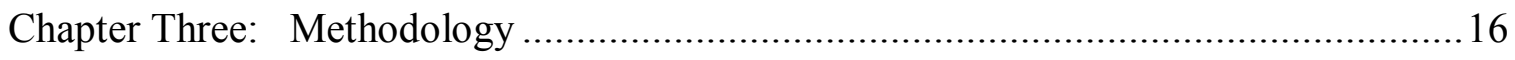

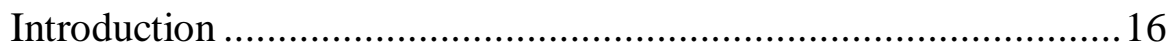

Population and sample .................................................. 16

Variables and measures........................................................ 18 


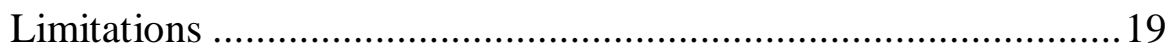

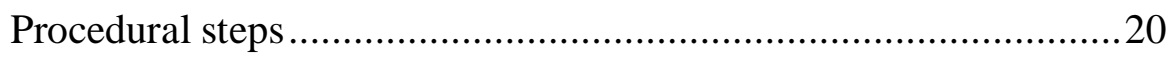

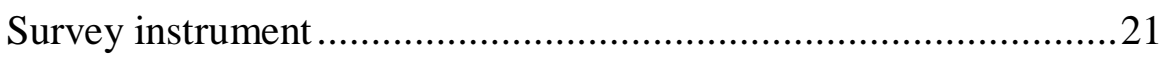

Ethical considerations and sampling method ................................22

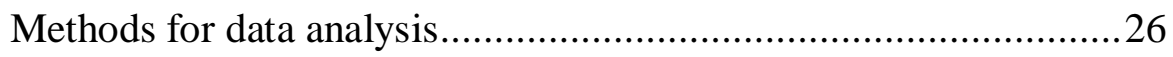

Validation and reliability ............................................................ 30

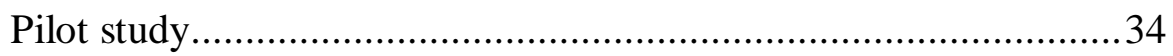

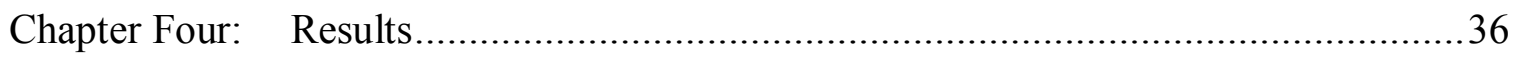

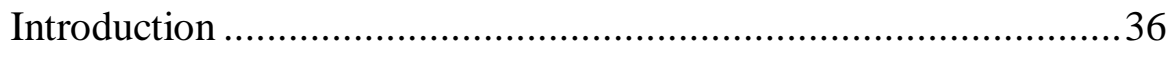

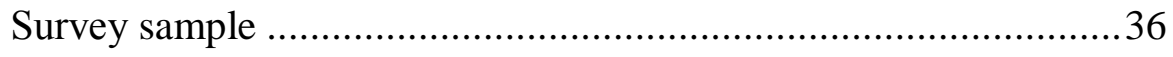

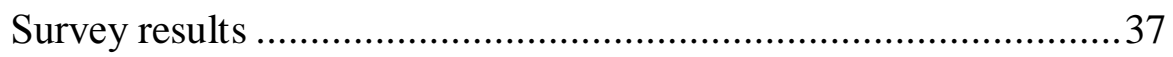

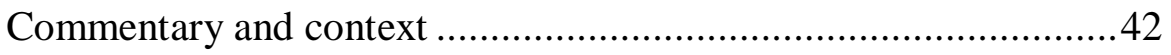

Teachers' purposes and perspectives ..............................................4

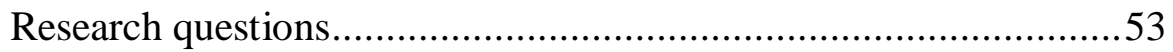

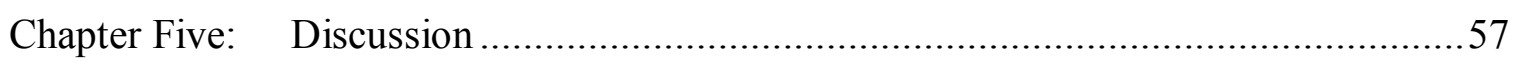

Prevalence of demonstrations .......................................................57

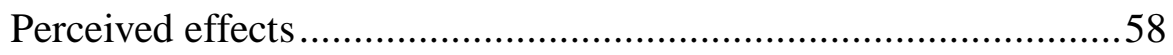

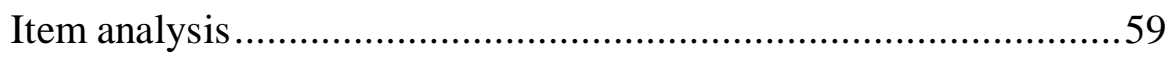

Incongruities within responses ...................................................61

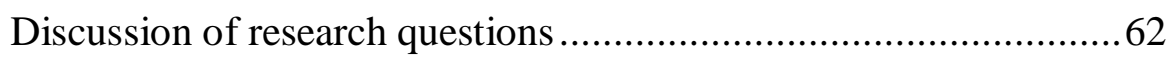

Chapter Six: Conclusion and Recommendations ..............................................66

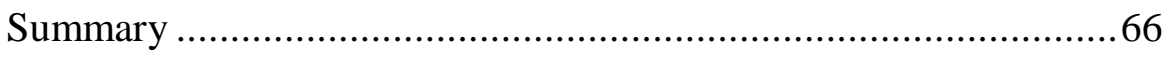

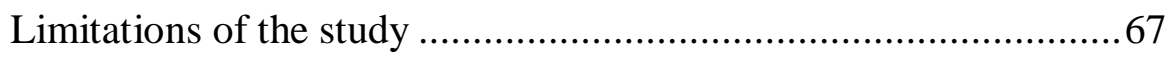


Recommendations for future research ...................................6 68

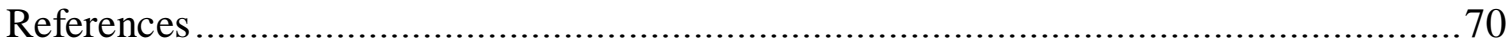

Appendix A: $\quad$ Informed Consent for Research Letter-Survey ..............................77

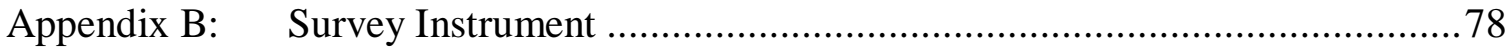

Appendix C: $\quad$ Survey Questionnaire Item Abstract Table ......................................81

Appendix D: Informed Consent for Research Letter-Extended Questionnaire ........82

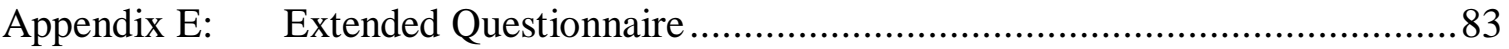

Appendix F: $\quad$ Extended Questionnaire Item Abstract Table .................................. 84

Appendix G: $\quad$ Survey Responses — Summary Tables ...................................... 85

Appendix H: $\quad$ Project Expenditures ....................................................... 91 


\section{Chapter One}

\section{Introduction}

\section{Context of the Study}

Observations of high school chemistry teachers' practices, and other anecdotal evidence, suggest that the use of classroom lecture demonstrations is widespread. Chemical suppliers offer prepackaged kits, and even accredited courses, to encourage and support the inclusion of such demonstrations in educators' daily practice (Sharpen existing skills, 2011). Chemistry and physics teachers at a number of schools employ attractive demonstrations to advertise course offerings and increase enrollment (Chemistry Program Review, 2008), with some institutions employing "full-time resource [staff] to develop, archive, and prepare lecture demonstrations" (The Mission of the YSU Chemistry Department, 2011). Whether inclusion of classroom demonstrations truly advances students' interest and understanding remains unverified. The absence of published literature regarding the extensiveness and perceived effectiveness of lecture demonstrations indicates an opportunity for research to benefit current and future chemistry teachers and science education programs.

\section{Definition of Lecture Demonstration}

Lecture demonstrations have been conducted in science classrooms for at least three centuries. Taylor (1988) traces education via demonstrations of scientific principles to the late seventeenth century, with eminent figures such as Robert Hooke appointed as early as 1662 to act as demonstrators for Fellows of the Royal Society. Taylor (1988, p. 
11) further states that "public demonstrations as part of a course of instruction" (which are presumably the equivalent of modern lecture demonstrations) began in 1694. There are certainly abundant references to classroom demonstrations illustrating specific scientific principles in academic literature of the intervening centuries. Michael Faraday used demonstrable phenomena as the basis of his famous 1827 and 1860-61 lecture series (see Faraday, 1904); more recently, texts such as those of Shakhashiri (1983, 1985, 1989, 1992, 2011a), Sprott (2006), and Shmaefsky (2004) feature hundreds of demonstrations for high school and college students of chemistry and physics.

Kauffman (1996) cites Jensen (1991) in claiming that early chemistry instruction was "solely by demonstration," although Kauffman's (1996) subsequent reference to the introduction of laboratory experience to students' education suggests that said demonstrations were a part of lecture-based courses used in lieu of learners' laboratory work and not the sole means of introducing concepts. Regardless, Kauffman (1996) presents a detailed history of the lecture demonstration, including what he terms a "golden age" of scientific demonstrations presented for students, but also for members of the public. Perhaps tellingly, one of the educators featured in Kauffman's (1996) article, Sir Humphry Davy, found that despite the consistent appeal of his demonstration-laden lectures, the society gentlemen in attendance were not motivated to further pursue scientific endeavors. Davy's observation is in contrast to a statement by Taylor (1988): "it [lecture demonstration] seems to work with all age groups and is a great way of inculcating a sense of excitement about science." The apparent contradiction is part of the focus of the research study. 
Taylor (1988) defines a demonstration as an "illustration of a point in a lecture or lesson by means of something other than conventional visual-aid apparatus." Presumably, laboratory investigations performed by students, although nominally covered under the aforementioned description, would not be considered "demonstrations"; we should amend the definition to explicitly state that the examples should be instructor-led, with students acting as a relatively passive audience rather than as participants. The resulting characterization appears to be a standard interpretation of the meaning of "lecture demonstration."

\section{Purpose of the Study}

The abundance of information related to performing classroom science demonstrations is an unsubtle suggestion that educators who do not include attentiongrabbing performances as part of their normal teaching are somehow remiss. Most of the published authors cited in this proposal presume that the use of science demonstrations is - or at least should be - practically universal, with promoters emphasizing the "charm" (Ramette, 1980) or "entertaining distraction" (Shmaefsky, 2005) afforded by lecture demonstrations. Less convinced are Roadruck (1993) and Swanson (1999), who posit several credible reasons why some educators might choose not to include demonstrations in their instruction. Neither, however, presents any research data to validate their rationales. Meyer et al. (2003) also suggest some reasons for educators not to employ lecture demonstrations, but offer what amounts to a straw-man argument apparently designed to favor their use. For example, their assertion that "many new teachers... have not been exposed extensively to the value and pedagogy of demonstrations and are 
uncomfortable with the thought of conducting them in class" implies that more experienced educators would most certainly incorporate lecture demonstrations - that unwillingness is merely due to teachers" inexperience, since the "value" of demonstrations is self-evident. Meyer et al. (2003) at the same time lament that “[u]nfortunately, quantitative education research does little to promote the use of demonstrations," and are apparently unwilling to recognize that a lack of support for their assumption may indicate a flawed premise.

It may be that educators have chosen to include or exclude demonstrations from their repertoire based on their own experiences — as students or as teachers - in the classroom. Data from the research study elucidate some of the reasons why teachers employ lecture demonstrations. In particular, educators were asked about their experience with demonstrations; concepts that are effectively taught using demonstrations; their familiarity with published research related to science demonstrations; and how—if at all—-they expect to alter their use of lecture demonstrations in their classrooms. Survey data, along with additional data from extended questionnaires, were therefore collected in order to address the following:

\section{Primary Research Questions}

RQ1. Do high school chemistry teachers routinely employ classroom demonstrations as part of their instruction?

RQ2. Do high school chemistry teachers perceive students' performance to be improved by the use of classroom demonstrations? 
RQ3. Do high school chemistry teachers perceive students' motivation to be enhanced by the use of classroom demonstrations?

RQ4. Is there a correlation between chemistry teachers' exposure as students to lecture demonstrations and their current use of classroom demonstrations?

RQ5. Is there a correlation between teachers' years of chemistry teaching experience and their use of classroom demonstrations?

RQ6. Is there a correlation between chemistry teachers' academic preparation (chemistry vs. "non-chemistry" degree) and their use of classroom demonstrations?

Minor Research Question

RQ7. What best-practice research related to classroom demonstrations guides high school chemistry teachers?

Significance of the study

Published literature mentions little about how extensive the use of lecture demonstrations in chemistry classrooms has become in the decades since their introduction. Demonstrations' advocates and skeptics alike are therefore expected to benefit from the mixed-methods research study, which seeks to both quantify the means by and extent to which lecture demonstrations are employed in high school chemistry classes and to elucidate the perspectives of a representative cross-section of educators. The resulting survey data indicate chemistry teachers' perceptions of the effect of classroom demonstrations on students' learning and motivation to study the subject 
further. Correlations among educators' years of science teaching experience, past exposure to lecture demonstrations, and frequency of their inclusion of demonstrations in their own teaching are indicated from analysis of quantitative data. 


\section{Chapter Two}

\section{Literature Review}

\section{Introduction}

Educators at all levels have ready access to information regarding classroom demonstrations. There is clearly much discussion devoted to the use of science

demonstrations, including differences of opinion regarding their merits (see Beall, 1996). The first section of the literature review will highlight some of the published justifications for the use of classroom demonstrations. Subsequent sections will discuss scholarly articles focused on various perceived benefits of lecture demonstrations, including greater motivation to learn the subject matter, improved understanding of concepts, and effective substitutes for active laboratory experience.

\section{Justifications for use of demonstrations}

A search of Internet resources produces a large number of sites dedicated to sharing science demonstrations, including those maintained by individuals (e.g. Spangler, 2010) whose careers are based on presenting demonstrations and marketing supplies for others to employ in the classroom. The author has already made reference to some of the texts (perhaps the best known of which are those of Shakhashiri) that are readily available to science educators; such publications typically provide detailed lists of necessary chemicals and apparatus in addition to discussions of the concepts exhibited in the demonstrations. 
Along with the recipes for presentation, the texts and Web sites proffer a philosophy underlying the use of classroom demonstrations: that because demonstrations are entertaining, they will spark deeper interest in the current topic and prompt students to further study the subject. Many published articles relating to demonstrations take up this theme; for example, Meyer et al. (2003) state that "educators can generate and renew vital interest in chemistry through the use of well planned and effectively presented classroom demonstrations that attract and engage the active and visual learners in today's classrooms." Ramette (1980), whose article is quoted extensively by Shakhashiri (1983), states that "the teacher who does not take advantage of demonstrations is doing his students a disservice" by failing to stimulate excitement in the audience.

There are certainly valid reasons for including demonstrations in introductory science courses; Swanson (1999) highlights one ostensible benefit to learners: "[j]ust as an artist uses a paintbrush to reveal an underlying concept, a science educator uses a demonstration as his or her tool to illustrate scientific principles. In both cases, the picture is worth a thousand words." Milne and Otieno (2007) have found lecture demonstrations important in forging personal relationships between the instructor and students, particularly for "urban students belonging to marginalized groups", where the inclusion of lecture demonstrations produced greater student engagement during, and after, the introduction of concepts. Shakhashiri (2011b), too, promotes the use of demonstrations to enhance learning by strengthening interpersonal relationships:

[w] hat we want to do is make connections. This is how we help our brain[s] change-by making connections. I want you to know why I, and many others, use chemical demonstrations to connect with people...do you see the potential for connections? ... These connections are used to inform...engage...educate... advocate... [and] persuade. 
Other justifications demand scrutiny, such as Swanson (1999)'s assertion that [d]emonstrations provide teachers with a way to motivate students to learn and retain knowledge of chemistry" and an impassioned declaration from Bent and Bent (1980):

[1]ecture experiments make chemical lectures demanding for lecturers, meaningful for philosophers, and interesting for students. They are highly motivational. They have immense heuristic value, tremendous rhetorical power, overwhelming persuasive force... If you don't see it, you won't believe it. And if you don't believe it you won't understand it. And if you don't understand it, you won't long remember it. The senses are important, not only for first discovering, but for receiving knowledge...

In particular, the converse of Bent and Bent's contention (that seeing leads to understanding) should not be presumed true, although it appears to be the basis for many demonstrations.

\section{Increased student motivation}

Definitions of motivation tend to be nebulous, and it is therefore prohibitively difficult to validate or refute any claims regarding the motivational effects of science demonstrations. Shakhashiri's (2011b) remarks could be construed as a claim that demonstrations lead to greater understanding of concepts, but could also be interpreted to mean that the relationships formed between the presenter and members of the audience, rather than the presentation itself, beget increased motivation to learn. Students' selfreported "motivation", however, is typically an indication of immediate interest-what Schraw and Lehman (2001) term "situational interest...spontaneous and contextspecific" - rather than of genuine desire to study and understand the underlying principles (defined by Schraw and Lehman (2001) as "personal interest...enduring and context-general"). 
The question of whether situational interest in a demonstration equates to improved desire to understand course topics and attraction toward further study of the subject remains largely unaddressed in the literature. While Bent and Bent (1980) and Swanson (1999) conflate the immediate appeal of an attention-grabbing diversion with long-term understanding of the underlying principles, Schraw and Lehman (2001)'s metastudy indicates that personal interest is not highly malleable. Lecture demonstrations may well increase situational interest, commanding attention to the color changes, explosions, and other alluring features of chemical demonstrations, but Schraw and Lehman (2001) find that, at least in some instances, such "seductive details (i.e. highly interesting, but unimportant information)" interfere with recall of more important information.

Waldman, Schechinger, and Nowick (1996), Ramette (1980), Schrempp (2008), and Haddock et al. (2008) are but a few authors who claim that exhibitions they conduct or promote lead to greater attention devoted to the principles being demonstrated, although none provide research-based evidence to support their contentions. Publication of such assertions implies a tacit endorsement of the claims, but testimonials, no matter how numerous or supportive, are inadequate substitutes for valid studies. Even Pierce and Pierce (2007), who are quite critical of demonstration-based instruction, apparently feel compelled to tout the "remarkable attention" that students pay to chemistry demonstrations, and declare that "[d]emonstrations help instructors provide motivation and inspiration in lecture classes, especially at introductory levels," without citing any source for this significant statement. 
Perhaps Pierce and Pierce are simply acknowledging the entertainment value of demonstrations, and are defining "motivation and inspiration" as students' attendant interest-however fleeting — in the spectacle before them. Other authors are more direct about their beliefs regarding the value of demonstrations. Ramette (1980) states that, "[g]ood demonstrations not only spice up a class session, but they also help to teach principles, and they help to build up general experimental knowledge of a sort which makes chemistry seem more real and less abstract," and mentions "opportunities for teaching through classroom demonstrations." Shmaefsky (2005) and Pierce and Pierce (2007) present a more qualified view of the efficacy of lecture demonstrations, cautioning educators to be aware of current research into effective demonstration assessment techniques.

Increased student learning

Even Ramette (1980), an early champion of demonstrations as a means of engagement, acknowledges that demonstrations should serve a purpose other than transforming teachers into "clowns in the classroom," and there appears to be scholarly consensus regarding the necessity of shifting learners from passive observation toward active construction of knowledge. Opportunities remain for research into the most effective means of introducing or reinforcing concepts using lecture demonstrations; Glasson (1989), Roth, McRobbie, Lucas, and Boutonné (1997), Lynch and Zenchak (2002), Fagen (2003), Meyer et al. (2003), Shmaefsky (2005), Pierce and Pierce (2007), and Baddock and Bucat (2008) all recommend somewhat different procedures for 
presentation methods and assessment of learning, and present differing outcomes from the methods they have examined.

It is not unreasonable for educators to expect improvements in students' understanding as a result of lecture demonstrations - educators apply particular instructional methodologies with the presumption that said techniques will lead to learning gains. A study published by House (2000) correlates data obtained by interviewing a large sample of 13-year-old students in Hong Kong with their performance on the 1999 TIMSS (Trends in International Mathematics and Science Study) exam. In the study, House determined that various instructional strategies, including classroom demonstrations, produced a significant effect on students' learning. In particular, multivariate regression analysis suggests that demonstrations by themselves (i.e. in the absence of other beneficial instructional techniques) account for a small percentage of the variance in the exam scores. The study does not, however, provide any detail regarding the definition of "demonstration" apart from its characterization as an activity performed by the teacher.

Crouch, Fagen, Callan, and Mazur (2004) state that learners must be actively engaged in order to realize gains in conceptual understanding; although the research of Buncick, Betts, and Horgan (2001) indicated increased student engagement, measures of performance and motivation (attitudinal) gains were inconclusive. Pierce and Pierce (2007) describe favorable learning outcomes arising from the use of demonstration assessments, wherein significant learning gains were produced on assessment items directly related to demonstrations as long as the demonstrations were unconnected to laboratory topics. Interestingly, midterm and final exam scores indicated that the Pierce 
and Pierce's treatment group—students who completed written post-demonstration assessments - did not perform better than the control group, and, on two of the three posttreatment exams, performed significantly worse.

Silberman (1983) discusses a deleterious effect of chemistry demonstrations, highlighting students' explanations of a common demonstration that illustrate their persistent misconceptions and apparent disinterest in determining the real explanation for observed phenomena. These findings are not the result of formal research, but Silberman's recommendations (“do [i.e. perform]...better demonstrations and...question students' understanding in order to improve observational and interpretive skills") are similar to those of later investigators such as Shmaefsky (2005) and Baddock and Bucat (2008). Clermont, Borko, and Krajcik (1993, 1994) suggest that improperly-performed demonstrations may lead to the introduction and entrenchment of misconceptions; a particularly attractive demonstration, explained incorrectly, may be harmful to students' understanding.

Considerable research investigating the effectiveness of various demonstration techniques in fostering learning gains has been conducted in the past decade, much of it skeptical. According to Fagen (2003),

[s]tudent evaluations suggest that demonstrations do serve to entertain and involve students in the lecture; one study found demonstrations to be among students' favorite elements of introductory undergraduate physics courses... [h] owever, there is less evidence indicating that lecture demonstrations help students understand the scientific principles underlying the demonstration. While instructors and students alike claim that students learn from demonstrations... there is little actual data to support this claim. 
Substitutes for laboratory experiences

Swanson (1999) suggests that demonstrations are sometimes necessary substitutes for students' laboratory experience. Others, though clearly supportive of the use of lecture demonstrations, are less bold. Beall (1996) comments: "[d]emonstrations have pedagogical value but are not an end in themselves... [they] are only one of many teaching techniques and shouldn't be used for their own sake." Roadruck (1993), citing the writings of cognitive theorist Piaget, flatly states that "demonstrations should not be a substitute for the hands-on laboratory work." Whether teachers of high school chemistry courses share this view of the purpose and value of classroom demonstrations is a focus of the proposed study; a dearth of information on this topic is evident.

\section{Summary of, and deficiencies in, literature}

Published articles regarding lecture demonstrations address the putative reasons for their inclusion in chemistry pedagogy. The absence of a solid research basis for claims of increased student learning and motivation, however, calls those claims into question. Research that might provide evidence to support or refute such contentions begins with the determination of why, and how often, classroom demonstrations are used by high school chemistry teachers.

One cannot reasonably determine the effectiveness of classroom demonstrations without a sense of their prevalence; the literature, however, is silent with respect to the extent to which lecture demonstrations are employed in high school and college classes. The research described herein, then, attempts to articulate the frequency and 
methodology of use, as well as the intended purposes and means of assessment, of demonstrations in high school chemistry classrooms. While measurement of gains produced by the use of lecture demonstrations may be the focus of further research, a sense of the perceived benefits arising from their inclusion in classroom instruction should provide an effective starting point for such investigations. 


\section{Chapter Three}

\section{Methodology}

Introduction

The purpose of the mixed-methods study is to address the research questions regarding the extent to which lecture demonstrations are used, and their perceived effects on students' understanding and motivation. While quantitative findings from survey data reveal definitively the extent to which classroom demonstrations are employed and educators' beliefs regarding their efficacy, selection of scaled-response items inadequately conveys teachers' rationales for their convictions. A sequential explanatory mixed-methods study, wherein qualitative interviews are utilized to illuminate detail underlying previously-collected quantitative survey data, is therefore warranted for the research study (Creswell \& Plano Clark, 2007; Ivankova, Creswell, \& Stick, 2006). Interviews of those whose survey responses exhibit anomalous data provide necessary context and "evidentiary power" (Sandelowski, 2003, in Plano Clark \& Creswell, 2008, p. 327), while inclusion of perspectives from those whose response sets are more representative of overall findings adds confirmatory power to the conclusions drawn from the survey data.

\section{Population and sample}

The sample frame for the investigation consisted of high school chemistry teachers working in the United States. A list of three hundred potential survey participants was populated by first choosing the state from which a high school would be 
selected, using a random number generator and the most recent national census data so that the chance of a state's selection was proportional to its population. Once a state had been chosen, a high school was selected from a comprehensive national database (accessible online at http://schooltree.org/high/), using another random number with boundaries set such that each high school in the state had an equal chance of selection. Following the identification of the high school, each chemistry teacher at the institution was given an equal chance of selection, either by random choice from a list published on the school's Web site, or — when insufficient data were available online — by asking the switchboard operator at the school to randomly choose an individual from the available pool of chemistry teachers. If the identified high school had no chemistry program, or was no longer operating, an entirely new selection of state and high school was performed to replace it.

The first fifty individuals (including two selected to replace defunct schools) from the list of three hundred were contacted and offered the opportunity to participate in the study. Thirty-three of the initial fifty teachers contacted returned survey data, with one returning the cash compensation along with the uncompleted survey instrument. The $66.0 \%$ response rate from the initial mailing suggested that surveys collected from forty more contacts should suffice to complete the data set (a minimum of fifty completed surveys). Consequently, forty more teachers were then selected in sequence from the larger list, and sent the same compensation and research documents as were provided to the initial set of contacts. One of the surveys sent to the second group was subsequently returned as undeliverable. Twenty of the thirty-nine teachers contacted in the second mailing $-51.3 \%$ of those to whom the instrument was sent - returned completed surveys; 
one of those respondents, although identified by his school as a chemistry teacher, indicated throughout the survey responses that he was instead a teacher of physics.

\section{Variables and measures}

Eight of the fourteen survey questions (see Appendix B) were quantitative, using balanced Likert scale items to assess perceived effects of lecture demonstrations on students' performance and motivation. The remaining survey items were of a more qualitative nature, addressing educators' prior experiences with classroom demonstrations, the frequency with which lecture demonstrations have been and will be employed, and teachers' educational backgrounds and years of experience teaching chemistry.

Interviews of each subject, although nominally preferable for maximizing validity of responses, are an unrealistic prospect. Consequently, a small subset (twelve high school instructors), chosen for maximum variety of experience and opinions, were selected from volunteer participants in the first-round survey. The medium by which extended questionnaires were completed—via electronic mail or telephone—was determined by mutual agreement of the researcher and survey participants. The same set of initial questions was asked of, and the informed consent statement read or sent to, each of the three telephone interview subjects and nine email correspondents. Once a participant had agreed to the consent statement and completed the initial telephone interview or email correspondence, follow-up questions were presented to those subjects whose responses required elaborations or clarifications. The combination of the two communications in each case provided the complete set of responses sought. 


\section{Limitations}

As the databases list schools by state, it was necessary to use a weighted probability (based on the relative populations of each state) in order to determine the state from which a particular contact was selected. This identification method was meant to give each chemistry teacher in the nation a reasonably equal chance of being chosen. It is possible that even this randomized selection process could have resulted in overrepresentation of certain demographics, particularly if potential respondents who refused to participate represent a particular socioeconomic category, but the initial sample should be of sufficient size to obviate this concern. When more than one chemistry teacher was associated with an identified high school, selection was performed as randomly as was possible. It is possible that selection bias on the part of school staff (who were contacted via telephone and asked for contact information for "a chemistry teacher in the building") or on the part of the researcher (when some, but not all, potential participants were listed on a school's or science department's Web site), resulted from such procedures. Given, however, that no selection criteria were communicated to school staff (who were asked to randomly choose a chemistry teacher in cases where multiple candidates were available), and that the researcher used a random-number generator to select from an online list of chemistry teachers at an institution, there is expected to be no bias toward teachers with more years of experience or toward those whose assignments include more advanced (Honors, Advanced Placement, or International Baccalaureate) courses. 
Procedural steps

Selected participants were contacted by email and/or telephone several days before the questionnaire was sent, informing them of their inclusion in the survey. A paper copy of the survey instrument-along with the informed consent statement, a selfaddressed stamped envelope, and a five-dollar cash incentive- - was sent to each identified subject at her or his work (school) address. Individuals who preferred not to complete the survey were asked instead to return the cash incentive, thereby indicating that contact was achieved. Additional compensation, in the form of a ten dollar donation to a reputable disaster relief organization, was offered on behalf of all participants who completed the survey. In cases where a contacted individual declined to participate, the next person on the list of prospective subjects was contacted according to the procedure described previously.

The fifty-two chemistry teachers who completed and returned surveys were offered the opportunity to participate in an interview, with an additional twenty dollar donation made to a reputable disaster relief organization on behalf of each individual completing the extended questionnaire via telephone or email. Responses to the extended questionnaire were qualitative in nature, addressing chemistry teachers' views of the structure and purposes of classroom demonstrations, as well as identifying concepts that educators perceived to be effectively introduced or reinforced using demonstrations. Although more than half of the survey participants initially agreed to further participation in the research process, follow-up contacts of those volunteers revealed that only some of them would be able to promptly complete the extended questionnaire via telephone 
interview or email correspondence. Twelve interviewees and correspondents were thus selected, based on their responses to the initial survey, in order to encompass the maximum possible variety of opinions regarding the purpose and merits of classroom demonstrations.

Participants were chosen, from those who expressed a willingness to be interviewed, so as to represent the broadest possible range of teaching experience, institutional socioeconomics, and geography. Particular effort was made to ensure the inclusion of multiple perspectives regarding the efficacy of classroom lecture demonstrations on students' motivation and performance. Although it was anticipated that fewer than the necessary ten extended questionnaires would be completed, necessitating yet more survey contacts in order to complete the set of interviews and correspondence, sufficient qualitative data were collected from the representatives of the fifty-two chemistry teachers who returned completed surveys, and no further contacts were necessary.

\section{Survey instrument}

A survey measuring the extensiveness of, and philosophy underlying, the use of science lecture demonstrations had not yet been published before the research project began, necessitating the development of an appropriate quantitative instrument for assessment of the frequency and perceived benefits of lecture demonstrations in science classrooms. A draft version of the survey was tested with three volunteer subjects, and revisions made to eliminate redundancies and unclear language as well as to optimize 
response categories. The revised instrument (see Appendix B) was further tested in a pilot study consisting of nine subjects.

\section{Ethical considerations and sampling method}

Initial contacts with prospective survey participants took place via email and/or telephone. Participants were informed that as recompense for their time, a token cash incentive would be provided, and that a charitable donation in the amount of ten dollars would be made to a reputable disaster relief organization upon completion of the survey. It was anticipated that a maximum of fifteen minutes would be required to complete the written survey; no participants indicated that the projected time commitment was inaccurate or that the compensation was inadequate. A U.S. mail based survey was chosen due to difficulties in contacting educators during the work day, and to increase rate and quality of responses by allowing selected participants to complete the survey at their leisure. The cash incentive and the appeal to participants' altruism were expected to produce immediate responses and a very high response rate, reducing the number of contacts necessary to obtain sufficient data. While the pilot study results suggested that a very high ( $77.8 \%$ response rate) could be expected, actual survey completion data -53 of 89 , or $59.6 \%$ - were more consistent with other surveys in which incentives were offered (Gregory, 2008) and produced slightly more than the targeted number (fifty) of completed surveys.

The author's own experience as a science educator suggests that personal contact via telephone during the workday is difficult to establish. Consequently, email was identified as the preferred means of notifying potential participants of the impending 
arrival of the survey. Teachers who could not be reached via email were contacted via telephone. Where personal contact via telephone was unsuccessful, a voicemail message was left, inviting the individuals to participate, mentioning the cash incentive and the charitable donation as incentives to complete the survey, and providing the contact information (telephone number and email address) of the researcher. Inclusion of the researcher's contact information permitted each individual to decline the invitation to participate, or to request further information regarding the research project.

Consequently, even though a direct personal contact was not always feasible, prospective participants were adequately informed of their selection and were able to complete the survey at a convenient time and at the researcher's expense.

The educators to be surveyed were selected with maximum attention to variation in geography, diversity of educators' experience, and institutional socioeconomics. Although the response rate was far less than $100 \%$, the respondents appeared to represent multiple demographics (such as public/charter or urban/suburban/rural schools), geographic areas (larger or smaller states), and years of chemistry teaching experience. The World Wide Web affords unprecedented access to educational institutions and personnel, and therefore finding a sufficient number of schools was not problematic. At the same time, particular effort was required in order to avoid oversampling institutions with popular or attractive Web pages should such features be the exclusive domain of affluent schools. In most cases, initial contact with participants was either through information available on school Web sites or through the school's main office. Where prenotice via email or telephone proved impossible to achieve, the informed consent statement and survey instrument were sent to the "Chemistry Teacher" at the identified 
institution. While the original proposal suggested that unidentifiable teachers would simply be replaced by the next person on the list of potential contacts, it was determined that this approach would cause urban schools to be disproportionately underrepresented, given that school personnel at several such institutions were unwilling to provide the requested contact information.

Random sampling methods should be more likely than convenience sampling to produce generalizable results, but are substantially more difficult to implement. A truly random sample should give each educator in the nation an equal chance of being selected, and would necessitate access to every high school. Even if the databases discussed previously cannot include all high schools in the United States, they certainly represent the most exhaustive and up-to-date lists of high schools available. It was anticipated, then, that selection of institutions via random-number generation using relative state populations should give each chemistry teacher approximately the same likelihood of selection. When more than one individual was responsible for teaching chemistry at an institution, another random choice was made, with each qualified teacher at the school given an equal chance of being selected for participation.

Any sampling method in which participants are chosen because of their accessibility is subject to coverage error; the researcher hoped to minimize the effects of coverage error by using the largest reasonable sample size given the constraints that define an appropriate participant (current employment as a chemistry educator), and by not limiting selection of individuals to those with easily available email addresses. One should expect an adequately large sample size to reduce random (sampling) error, so that the results from the survey sample approximate the results one would anticipate in the 
larger population. Neither coverage nor sampling error can be completely eliminated, but a thoughtful design should reduce the negative consequences of either.

Studies show that response rates for U.S.-mailed hard-copy surveys are no worse than for electronic surveys; Kaplowitz, Hadlock, and Levine (2004) indicate that participants receiving U.S.-mailed prenotice are just as likely to complete a hard-copy mailed survey as a Web-based survey. Inclusion of a cash incentive, however, necessitated contact via U.S. mail, rendering a Web-based process impractical. It was anticipated that providing the survey, incentive, and a stamped return envelope in a single mailing would prompt participants to complete the short, paper-based instrument upon receipt, a process likely to be more convenient and immediate than visiting a Web site to fill out the survey.

It was thought likely that email would be the least costly, least intrusive, and most efficient means of contacting prospective survey and interview participants. Fortunately, a recent study by Porter and Whitcomb (2007) suggests that email is as effective as U.S. mail as a pre-notification technique for surveys. In addition, email addresses and telephone numbers would be available for use later in the process, such as for follow-up contacts to remind those who have neglected to return the survey or complete the extended (interview) questionnaire.

Regardless of the survey method employed, processing of data is necessary. Spreadsheet software often allows export of quantitative and categorical data, in raw or summary form, from which statistical analysis can readily be performed. Human processing was required to enter quantitative data as well as to manage answers to the open-response items; it was anticipated (and subsequently found) that quantitative 
responses could be entered quickly, and that much of the open-response data would fit into categories, hastening the processing somewhat.

Numerical coding of return envelopes was used to determine response rate, to identify prospective interview candidates, and to preserve the anonymity of those who did not wish to participate further in the research. Original paper copies of the surveys were marked with the number corresponding to the envelope code, and data without personally identifying information transferred from the coded pages into the spreadsheet for processing. Coded survey responses, interview data, and structured correspondence were maintained on password- and biometric-secured personal computers, with numerical codes removed from responses when survey findings, interview responses, and data from structured correspondence were collected into a single document for analysis.

\section{Methods for Data Analysis}

Survey responses were analyzed in order to select the appropriate range of interview candidates, who were chosen from willing survey participants in order to encompass the range of responses exhibited. Initial qualitative analysis began during collection of interview and structured correspondence data, so that follow-up questions could be addressed in a timely manner and so that it was clear when sufficient data had been obtained. The researcher used holistic analysis (a discussion of the entire case) and embedded analysis (discussion of individual aspects of the case), as both are deemed appropriate for identification and analysis of important themes. Throughout the analysis, the twin goals of allowing subjects to communicate opinions and experiences, and of informing all contributors to the education process, were kept in mind. 
The researcher analyzed qualitative interview and structured correspondence data according to the case study method described by Hatch $(2002$, p. 30) as "a contextualized contemporary... phenomenon within specified boundaries"; said phenomena may include “a process, an institution, or a social group" (Merriam, 1988, in Hatch, 2002, p. 30).

Although the interview subjects and email correspondents were selected from multiple institutions, their common experience as chemistry teachers unites them as participants in a process. Using a case study as the research method allows the researcher to “explore... a bounded system (case)...over time, through detailed, in-depth data collection... and report a case description and case-based themes" (Creswell, 2007, p. 73). According to Yin (2003, in Creswell, 2007, p. 75), case study data typically consist of the following: "documents, archival records, interviews, direct observations, participant-observation, and physical artifacts". Hatch (2002) does not demand that the researcher's data include "multiple sources of information" (Creswell, 2007, p. 73) in order to produce an effective case study, arguing instead that the focus on "bounded systems" (Smith, 1979, in Hatch, 2002, p. 31) defines the nature of a case study. In the proposed research, then, interviews of, and correspondence with, participants represent the bulk of the qualitative data collected. Hatch (2002, p. 23) defines such an approach as an "interview study" - a category that Creswell (2007) does not include as a discrete classification.

The case study method was deemed to be the most applicable approach to analyzing the qualitative data. While an ethnographic model was considered, the focus of the research is not on "issues such as power, resistance, and dominance" (Creswell, 2007, p. 70) but instead on revealing the sources of chemistry teachers' beliefs regarding the 
value of classroom demonstrations. As the study's data are not related to a singular experience, a phenomenological approach is inappropriate for the proposed research. A grounded theory approach has some appeal, but the intent of the proposed study is to determine, rather than to explain, educators' attitudes and philosophies. Creswell's (2007) fifth category, narrative research, is singularly inapt, with its focus "stories of individual experiences" (Creswell, 2007, p. 78) instead of the intended discussion of a group's behaviors and beliefs.

As structured correspondence, interview data, and survey responses address educator's self-reported beliefs, corroborating evidence is necessarily absent; inclusion of valuable supporting data such as exam scores and assignment completion rates, even if available, may violate confidentiality of participants and non-participants alike. It is still necessary, however, to buttress subjects' opinions via triangulation. Stake (1995, p. 173) defines triangulation as a process of "working to substantiate an interpretation or to clarify its different meanings." In the absence of impersonal data such as changes in course or assignment completion rates, triangulation must result from the overlap of multiple subjects' perspectives. Even though the study focuses on opinions-teachers' perceptions of motivation and success related to their presentation of classroom demonstrations - the viewpoints expressed by interviewees and correspondents should be externally supported, lest the experience of a single person be viewed as the definitive word on the issue. At the same time, Creswell (2007, p. 120) advises the inclusion of an “"atypical'... or a 'maximum variation' or 'extreme' case"; the purpose of such examples in a collective case study such as this is to ensure that the "sampling strategy... represent $[\mathrm{s}]$ diverse cases and...fully describe[s] multiple perspectives about the cases." 
Stake (1995, p. 57) praises an approach in which subjects are chosen for "variety but not necessarily representativeness...the primary criterion [being] opportunity to learn."

Participants in the case study consisted of volunteer educators who have had recent experience with classroom chemistry demonstrations. The inclusion of multiple perspectives should increase the validity and applicability of the findings; even if individuals share differing overall views regarding the motivational and learning effects of classroom demonstrations, points of agreement within their separate experiences serve to support the themes revealed in the interviews and correspondence.

Following the final phase of data collection (interviews and structured correspondence), detailed quantitative analysis was performed on the survey responses, and any additional qualitative analysis was completed. The final report thus includes a discussion of all of the data obtained and the conclusions that arose from the quantitative results as well as from the intersection of qualitative and quantitative findings. Analysis of the survey data, interview responses, and correspondence could allow the researcher to modify the survey instrument in order to obtain additional quantitative data from future studies pertaining to the frequency, methodology, and purpose of lecture demonstrations.

Quantitative statistical analysis was performed once surveys, interviews, and correspondence had been completed. Survey data were used to determine correlations among chemistry teachers' use of classroom demonstrations and their:

exposure to demonstrations as students

years of experience in chemistry teaching degrees or training in science familiarity with research related to classroom demonstrations. 
perceptions of the effects on demonstrations on students' performance and interest.

This research could serve as a starting point for investigations focusing on learning gains associated with demonstrations. Such follow-up studies would likely emphasize quantitative analysis in order to improve the applicability of the findings.

\section{Validation and reliability}

As no similar instruments have been published, validation of the proposed survey by comparison (i.e. determining concurrent criterion validity) is impossible. Of course, if similar instruments exist, there would little advantage in developing a new survey to address the same issue. Individual items, such as the number of times teachers perform classroom demonstrations, could be validated through the use of follow-up observations of educators' behavior (predictive validity), although the entire instrument will still not be validated in this fashion. Initially, a pilot survey buttressed by telephone interviews and email correspondence should improve the validity of the instrument; if interviews and correspondence reveal confusion regarding survey items, or indicate that available response options inadequately capture teachers' opinions, the instrument could be restructured and retested until interview and survey responses become congruent. For the full investigation, sheer numbers are likely to be helpful in establishing the ability of the instrument to accurately assess the perceptions and actions of classroom teachers. The result is improved face validity — the weakest measure of validity, but the only measure applicable to this study. 
Reliability, by contrast, is far easier to determine. The most likely means of ensuring reliability is to use alternate forms of the instrument with a large sample split into halves. For the specific instrument under discussion, alternative forms could involve reversing the order of response sets (greatest-to-least and least-to-greatest). It is more likely, though, that reliability would be established more effectively by changing the order of question sets. Answers to questions about students' performance may affect responses to subsequent questions regarding students' interest, and therefore a reversal of the sets for half of the respondents (i.e. interest-related questions placed before performance-related items) should assist in determining whether answers to earlier questions affect responses to later items. Ultimately, the same form of the survey was used for all participants, as it was impossible to anticipate the number of participants that would complete each of the different forms. A repeat administration, using the aforementioned reversal of sets, would be necessary in order to assess the consistency of the instrument in accurately capturing teachers' opinions regarding the effects on students' motivation and performance. Other means of determining reliability, such as testing-retesting or use of alternative observers, appear to be inappropriate in a survey that measures opinions rather than actual performance. Repetition of items could increase internal consistency, but the increased length of the resulting instrument would be likely to depress response rates or engender fatigue in the participants.

Recognition of the investigator's bias has been hailed as a strength of qualitative research, as though admission of the researcher's preconceptions automatically obviates concerns regarding the validity of findings. Indeed, Hiles (1999) states that "researcher bias can be a problem, but it is dealt with by being brought out into the open and 
acknowledged." Acknowledgement, however, is insufficient; inherent researcher bias necessitates verification of themes identified in the data.

Morse, Barrett, Mayan, Olson, and Spiers (2002) argue "that qualitative researchers should reclaim responsibility for reliability and validity by implementing verification strategies integral and self-correcting during the conduct of inquiry itself" in order to "[move] the responsibility for incorporating and maintaining reliability and validity from external reviewers' judgements [sic] to the investigators themselves." Posthoc data verification methodologies common in current practice, such as member checking and audit trails, are thereby deemed inadequate:

Using standards for the purpose of post-hoc evaluation is to determine the extent to which the reviewers have confidence in the researcher's competence in conducting research following established norms. Rigor is supported by tangible evidence using audit trails, member checks, memos, and so forth. If the evaluation is positive, one assumes that the study was rigorous. We challenge this assumption and suggest that these processes have little to do with the actual attainment of reliability and validity. Contrary to current practices, rigor does not rely on special procedures external to the research process itself (Morse et al., 2002).

Although member checking can be helpful in verifying the authenticity of individuals' statements, and was used to that effect in the analysis section of this research project, Morse et al. (2002) state that member checking does nothing to validate the researcher's conclusions: "[t]he problem of member checks is that, with the exception of case study research and some narrative inquiry, study results have been synthesized, decontextualized, and abstracted from (and across) individual participants, so there is no reason for individuals to be able to recognize themselves or their particular experiences." This research study is not exempt from such concerns, despite its grounding in the case 
study tradition. Multiple viewpoints should illuminate the themes, but the researcher employing member checking should expect nothing other than pro forma acceptance from the subjects of the study, who lack access to the full data set and thus to the wider perspective. Again, Morse et al (2002): "investigators who want to be responsive to the particular concerns of their participants may be forced to restrain their results to a more descriptive level in order to address participants' individual concerns. Therefore, member checks may actually invalidate the work of the researcher [by keeping] the result of the analysis inappropriately close to the data."

Morse et al. (2002) call for "strategies for ensuring rigor [that] must be built into the qualitative research process per se", including "investigator responsiveness, methodological coherence, theoretical sampling and sampling adequacy, an active analytic stance, and saturation...forc[ing] the researcher to correct both the direction of the analysis and the development of the study as necessary, thus ensuring reliability and validity of the completed project."

Also, Morse et al. (2002) suggest that the responsive investigator will analyze data as it is collected in order to construct inferences and queries that will determine both the future course of the research and additional participants necessary to confirm, reproduce, or refute initial results. This latter aspect is of greatest significance; the preconceptions of the researcher may not be supportable by the data, and the investigator must always be open to reconsideration of his or her thesis. Reassessment need not be confined to themes, either; the data-gathering methodology should also be subject to continuous review, so that rigid adherence to the initial plan does not interfere with the investigator's ability to produce the conclusion that the data would suggest. 
Validity of the findings is enhanced through the inclusion of multiple viewpoints, including those in diametric opposition. Despite the expected difference in perspective, the use of multiple subjects within the case should produce the desired data and theory triangulation (Denzin, 2006). The use of disconfirming data-exceptions that prove the rule - reveals, and adds richness to, the true - likely unanticipated — themes that ultimately emerge.

\section{Pilot study}

A pilot study was conducted for the purpose of devising a contact and compensation process intended to maximize response rate and quality of responses. Ten subjects, selected according to the protocol described previously, were mailed copies of the survey questionnaire. The very low response rate $(20.0 \%)$ suggested that most of the surveys were discarded, perhaps before being read by the intended recipients.

Consequently, it was decided that email or telephone prenotice would be used to alert prospective participants. In addition to the pre-survey notice, a small cash incentive was included with the next set of nine questionnaires, with the expectation that recipients would either complete the survey or return the incentive; receipt of either the completed questionnaire or the cash would indicate to the investigators that successful contact had been made.

Seven of the nine surveys composing the second set were completed and returned, and one blank questionnaire was returned along with the cash incentive. Neither the questionnaire nor the incentive was returned by the ninth subject; as no response to repeated emails was received, the researcher surmises that the selected individual was no 
longer employed by the institution. The second-set completion rate of $77.8 \%$ suggests that the combination of prenotice and cash incentive were effective in persuading busy teachers to share their perceptions of, and experiences with, classroom lecture demonstrations.

Response sets from the pilot study were entirely complete, indicating that the survey items were understandable and that the options provided were adequate to express teachers' opinions and experiences. Analysis of means and standard deviations for the quantitative items (items $1-8,12$, and 13) indicate a satisfactorily broad range of responses for each question, and qualitative responses (items 9 - 11) likewise displayed a variety of answers. The data collected from nine completed surveys appear adequate to justify use of the survey without changes to the questionnaire. Following the pilot study surveys, two respondents indicated in their survey responses a willingness to be interviewed and subsequently completed an email questionnaire. As the objective of the interviews in the pilot study is to improve the extended questionnaire for the core research project, responses were examined for clarity and completeness. Neither of the response sets obtained via email correspondence necessitated clarification or follow-up questions, so no revisions were made. 


\section{Chapter Four}

\section{Results}

Introduction

The survey consisted of two major parts: a selected-response section, in which options were presented in the form of a balanced Likert scale, and an open-response section. The selected-response section was further divided into two segments consisting of four items each; the two segments addressed perceived effects of classroom lecture demonstrations on students' performance and motivation, respectively. The openresponse section requested information regarding chemistry teachers' prior exposure to lecture demonstrations, the frequency with which the teachers now (and plan to) employ such demonstrations, educators' years of teaching experience, and their educational background (degree specializations). Interviews and structured correspondence addressed chemistry teachers' definitions of and practices regarding classroom lecture demonstrations, concepts addressed via demonstration, the role of teachers and students in the performance of demonstrations, and familiarity with existing research regarding lecture demonstrations.

\section{Survey sample}

A list of three hundred potential survey participants was constructed by randomly selecting their institutions from a comprehensive national database of high schools (available online at http://schooltree.org/high/). A total of ninety surveys-including return envelopes, informed consent statements, and a five-dollar cash incentive-were 
distributed; of these, fifty-three were completed and returned (including one from a physics teacher who had mistakenly been identified by personnel at his school as a teacher of chemistry). One survey was returned as undeliverable, and one survey was returned uncompleted along with the cash incentive. The response rate of 59.6\% (53 of 89) was deemed adequate, in that survey data were collected from slightly more than the minimum fifty participants after two sets of initial contacts, and no additional surveys were sent.

Survey results

The selected-response section of the survey comprised eight items. For each of the eight items, scores of 1 and 2 represented strongly and slightly negative perceived effects, respectively, while scores of 4 and 5 indicated, respectively, slightly and strongly positive perceived effects. A score of 3 represented no perceived effect.

Survey items $1-4$ addressed the perceived effect of classroom lecture demonstrations on students' performance on homework assignments, laboratory work, and exams, as well as their understanding of course concepts. The mean score reported for item 1 ("How are students' homework assignment scores affected by viewing classroom demonstrations?') was $\bar{x}=3.90( \pm 0.196, \alpha=0.05, n=52)$, with standard deviation $s=0.721$. For item 2 (“How are students' lab assignment scores affected by viewing classroom demonstrations?"), $\bar{x}=4.27( \pm 0.153, \alpha=0.05, n=52), s=0.564$. The mean and standard deviation for item 3 scores ('How are students' exam scores affected by viewing classroom demonstrations?") were $\bar{x}=4.10( \pm 0.155, \alpha=0.05, n=52), s=0.569$, and for item 4 (“'How is students' understanding of chemistry concepts affected by viewing 
classroom demonstrations?") were $\bar{x}=4.60( \pm 0.135, \alpha=0.05, n=52), s=0.495$ (see

Table 4.1). 
Table 4.1: Perceived effects of demonstrations on student performance

1. How are students' homework assignment scores affected by viewing classroom demonstrations?

\begin{tabular}{|c|c|c|c|c|c|c|c|c|}
\hline \multicolumn{4}{|c|}{ number of scores in category } & \multicolumn{4}{c|}{ statistical data } \\
\hline \multirow{2}{*}{1} & 2 & 3 & 4 & 5 & $\begin{array}{c}\text { number of } \\
\text { item scores } \\
n\end{array}$ & $\begin{array}{c}\text { mean of } \\
\text { item scores } \\
\bar{x}\end{array}$ & $\begin{array}{c}\text { standard } \\
\text { deviation } \\
(\alpha=0.05)\end{array}$ & $s$ \\
\hline 0 & 1 & 13 & 28 & 10 & 52 & 3.90 & \pm 0.196 & 0.721 \\
\hline
\end{tabular}

2. How are students' lab assignment scores affected by viewing classroom demonstrations?

\begin{tabular}{|c|c|c|c|c|c|c|c|c|}
\hline \multicolumn{4}{|c|}{ number of scores in category } & \multicolumn{4}{c|}{ statistical data } \\
\hline 1 & 2 & 3 & 4 & 5 & $\begin{array}{c}\text { number of } \\
\text { item scores }\end{array}$ & $\begin{array}{c}\text { mean of } \\
\text { item scores } \\
n\end{array}$ & $\begin{array}{c}\text { 95\% confidence interval } \\
(\alpha=0.05)\end{array}$ & $\begin{array}{c}\text { standard } \\
\text { deviation }\end{array}$ \\
\hline 0 & 0 & 3 & 32 & 17 & 52 & 4.27 & \pm 0.153 & 0.564 \\
\hline
\end{tabular}

3. How are students' exam scores affected by viewing classroom demonstrations?

\begin{tabular}{|c|c|c|c|c|c|c|c|c|}
\hline \multicolumn{4}{|c|}{ number of scores in category } & \multicolumn{4}{c|}{ statistical data } \\
\hline \multirow{2}{*}{1} & 2 & 3 & 4 & 5 & $\begin{array}{c}\text { number of } \\
\text { item scores }\end{array}$ & $\begin{array}{c}\text { mean of } \\
\text { item scores } \\
n\end{array}$ & $\begin{array}{c}\text { standard } \\
\text { deviation } \\
(\alpha=0.05)\end{array}$ & $s$ \\
\hline 0 & 1 & 3 & 38 & 10 & 52 & 4.10 & \pm 0.155 & 0.569 \\
\hline
\end{tabular}

4. How is students' understanding of chemistry concepts affected by viewing classroom demonstrations?

\begin{tabular}{|c|c|c|c|c|c|c|c|c|}
\hline \multicolumn{4}{|c|}{ number of scores in category } & \multicolumn{5}{c|}{ statistical data } \\
\hline \multirow{2}{*}{1} & 2 & 3 & 4 & 5 & $\begin{array}{c}\text { number of } \\
\text { item scores }\end{array}$ & $\begin{array}{c}\text { mean of } \\
\text { item scores } \\
\bar{x}\end{array}$ & $\begin{array}{c}\text { standard } \\
\text { deviation } \\
(\alpha=0.05)\end{array}$ & $s$ \\
\hline 0 & 0 & 0 & 21 & 31 & 52 & 4.60 & \pm 0.135 & 0.495 \\
\hline
\end{tabular}

"number of scores in category" refers to the number of responses selected for each Likert-scale option, where " 1 " represents "strongly negative effect", " 2 " represents "slightly negative effect", “3” represents "no effect”, "4" represents "slightly positive effect", and " 5 " represents "strongly positive effect." 
Items $5-8$ addressed chemistry teachers' perceptions of the effect of classroom lecture demonstrations on students' motivation to perform well on homework assignments, laboratory work, and exams, and to study the subject further (through additional coursework). The mean and standard deviation for item 5 ("How is students' motivation to perform well on homework assignments affected by viewing classroom demonstrations?") were $\bar{x}=3.54( \pm 0.182, \alpha=0.05, n=52), s=0.670$. For item 6 (“How is students' motivation to perform well on lab assignments affected by viewing classroom demonstrations?"), $\bar{x}=3.83( \pm 0.192, \alpha=0.05, n=52), s=0.706$. The mean and standard deviation for item 7 scores were ("How is students' motivation to perform well on exams affected by viewing classroom demonstrations? ”) $\bar{x}=3.60$ ( \pm 0.180 , $\alpha=0.05, n=52$ ), $s=0.664$, while for item 8 ("How is students' motivation to study this subject further (additional courses at this school or beyond) affected by viewing classroom demonstrations?") $\bar{x}=4.35( \pm 0.169, \alpha=0.05, n=52)$ and $s=0.623$ (see Table 4.2). 
Table 4.2: Perceived effects of demonstrations on student motivation

\section{How is students' motivation to perform well on homework assignments affected by viewing classroom demonstrations?}

\begin{tabular}{|c|c|c|c|c|c|c|c|c|}
\hline \multicolumn{4}{|c|}{ number of scores in category } & \multicolumn{4}{c|}{ statistical data } \\
\hline 1 & 2 & 3 & 4 & 5 & $\begin{array}{c}\text { number of } \\
\text { item scores } \\
n\end{array}$ & $\begin{array}{c}\text { mean of } \\
\text { item scores } \\
\bar{x}\end{array}$ & $\begin{array}{c}\text { s5\% confidence interval } \\
(\alpha=0.05)\end{array}$ & $\begin{array}{c}\text { standard } \\
\text { deviation }\end{array}$ \\
\hline 0 & 0 & 29 & 18 & 5 & 52 & 3.54 & \pm 0.182 & 0.670 \\
\hline
\end{tabular}

\section{How is students' motivation to perform well on lab assignments affected by viewing classroom demonstrations?}

\begin{tabular}{|c|c|c|c|c|c|c|c|c|}
\hline \multicolumn{4}{|c|}{ number of scores in category } & \multicolumn{4}{c|}{ statistical data } \\
\hline \multirow{2}{*}{1} & 2 & 3 & 4 & 5 & $\begin{array}{c}\text { number of } \\
\text { item scores }\end{array}$ & $\begin{array}{c}\text { mean of } \\
\text { item scores } \\
\bar{x}\end{array}$ & $\begin{array}{c}\text { standard } \\
\text { deviation } \\
(\alpha=0.05)\end{array}$ & $s$ \\
\hline 0 & 0 & 18 & 25 & 9 & 52 & 3.83 & \pm 0.192 & 0.706 \\
\hline
\end{tabular}

\section{How is students' motivation to perform well on lab assignments affected by viewing classroom} demonstrations?

\begin{tabular}{|c|c|c|c|c|c|c|c|c|}
\hline \multicolumn{4}{|c|}{ number of scores in category } & \multicolumn{4}{c|}{ statistical data } \\
\hline \multirow{2}{*}{1} & 2 & 3 & 4 & 5 & $\begin{array}{c}\text { number of } \\
\text { item scores }\end{array}$ & $\begin{array}{c}\text { mean of } \\
\text { item scores } \\
\text { (t) }\end{array}$ & $\begin{array}{c}\text { 95\% confidence interval } \\
(\alpha=0.05)\end{array}$ & $\begin{array}{c}\text { standard } \\
\text { deviation }\end{array}$ \\
\hline 0 & 1 & 23 & 24 & 4 & 52 & 3.60 & \pm 0.180 & 0.664 \\
\hline
\end{tabular}

8. How is students' motivation to study this subject further (additional courses at this school or beyond) affected by viewing classroom demonstrations?

\begin{tabular}{|c|c|c|c|c|c|c|c|c|}
\hline \multicolumn{4}{|c|}{ number of scores in category } & \multicolumn{5}{c|}{ statistical data } \\
\hline \multirow{2}{*}{1} & 2 & 3 & 4 & 5 & $\begin{array}{c}\text { number of } \\
\text { item scores } \\
n\end{array}$ & $\begin{array}{c}\text { mean of } \\
\text { item scores } \\
\bar{x}\end{array}$ & $\begin{array}{c}\text { 95\% confidence interval } \\
(\alpha=0.05)\end{array}$ & $\begin{array}{c}\text { standard } \\
\text { eviation } \\
s\end{array}$ \\
\hline 0 & 0 & 4 & 26 & 22 & 52 & 4.35 & \pm 0.169 & 0.623 \\
\hline
\end{tabular}

"number of scores in category" refers to the number of responses selected for each Likert-scale option, where " 1 " represents "strongly negative effect", " 2 " represents "slightly negative effect", "3" represents "no effect", "4" represents "slightly positive effect", and "5" represents "strongly positive effect." 
Results from survey item 9 ("In your experience as a student, approximately how many times per week (per five class days), on average, did your chemistry instructor perform classroom demonstrations?") and item 10 (“How many times per week (per five class days), as a teacher of chemistry, do you perform classroom demonstrations?") indicate that most teachers who returned the survey had witnessed chemistry demonstrations as students (37 of 49, with three respondents unable to recall), with all but one (51 of 52) indicating that they perform lecture demonstrations as part of their own chemistry instruction. The reported frequency of demonstrations ranged from less than one per month to more than four times per five class meetings. In response to survey item 11 ("To what extent do you plan to change the number of classroom demonstrations that you perform in the classes that you teach?"), all participants $(n=52)$ indicated that they planned to maintain or increase the number of lecture demonstrations they perform. The reported amount of total science teaching experience (item 12) ranged from 1 to 44 years $(\bar{x}=15.6, s=11.2, n=52)$, with specific experience in teaching chemistry (item 13) also ranging between 1 and 44 years $(\bar{x}=13.1, s=11.2, n=52)$. A variety of degree specializations were reported (item 14), with 36 of 52 surveyed chemistry teachers (69.2\%) indicating a degree featuring a major or minor concentration in chemistry or in a closely-related field such as chemical engineering or biochemistry.

\section{Commentary and context}

Although the selected-response items $(1-8)$ of the survey did not specifically invite elaboration, a few of the respondents included comments that provided some justification of their numerical responses. Such commentary tended to support statements 
made in their responses to items 10 and 11 , which were open-ended questions related to the frequency of current and future use of lecture demonstrations. One survey respondent declared that "after doing this survey, I am inclined to do more [demonstrations];" another averred that "I plan for them to get better every year, just like me," and a third asserted: "wish I had time to do a demonstration a day!" Several respondents clearly articulated the philosophy underlying their use of classroom demonstrations, offering statements such as "[i]deally, all lessons should be demonstrated. Students LOVE the demonstrations and do understand the concepts taught much better", "my students remember years after having my classes the demos that I did" and "critical for student interest...[I] try to make them a priority."

Other educators expressed more nuanced views of the benefits of demonstrations: one participant maintained that "[s]tudents like most of them, but...learn best about the topics and thinking critically by doing labs and applying concepts...”, while another indicated that "[i]f I believe it will benefit and enhance my students' conceptual understanding...I would add new ones." Even the forty-two year veteran who flatly stated that "I know that demonstrations help concept development" added that learners "are either motivated to do well...or not. If they have little interest, demonstration[s] don't seem to have much effect." Only one commenter expressed a neutral perspective; despite her occasional (once per week) use of demonstrations, and a strongly positive view of their effect on students' performance, this teacher's clearly-articulated conviction was "I feel student hands-on labs are better."

All of the participants in the survey expressed intent to maintain or increase the number of classroom demonstrations to be performed (item 11). Such a finding is not 
unexpected, given the enthusiasm for demonstrations evinced in the scores provided in the selected-response section of the survey, but the absence of any plans to decrease the number of demonstrations is noteworthy. The single chemistry teacher proposing that chemistry demonstrations might have some negative effect (perceiving slightly negative effects on students' homework and exam performance, as well as slightly reduced motivation to perform well on exams) nevertheless plans to increase the number of classroom demonstrations from "at least tw[o] every [three] weeks" to "at least one every week." Multiple attempts to contact this individual to further discuss this incongruity were unsuccessful.

\section{Teachers' purposes and perspectives}

While quantitative survey data indicate educators' beliefs regarding the effect of lecture demonstrations on students' performance and motivation, interviews and structured correspondence with twelve chemistry teachers reveal the means of, and reasons for, employing demonstrations as part of chemistry instruction. Despite significant differences in educational background, number of students served, and school demographics, the teachers who provided answers to extended questionnaires — via telephone or email - articulated consistent themes regarding the purpose of demonstrations in the chemistry classroom.

Subjects participating in interviews or structured correspondence reported chemistry teaching experience ranging from one to thirty-two years. The mean years of chemistry teaching experience exhibited by teachers in the interview and correspondence group $(\bar{x}=12.8, s=9.81, n=12)$ and in the larger group of survey participants 
$(\bar{x}=13.1, s=11.2, n=52)$ were not significantly different $(p=0.905)$. Nine of the twelve interviewees and correspondents $(75.0 \%)$ indicated a major or minor degree concentration in chemistry, a percentage slightly greater than, but not inconsistent with, the $69.2 \%$ rate evinced by all survey participants. Degrees held ranged from bachelor's to doctorates. Educators from rural, suburban, and urban schools were represented, including public, private secular, and religious-affiliated institutions.

Perceptions of the effectiveness of demonstrations varied among interviewees and correspondents. Teacher $\mathrm{K}$ was among the most neutral of all respondents, reporting an aggregate score of $X=15$ for items $1-4$ related to students' performance (vs. the group mean aggregate $\bar{x}=16.9$, such that $z=-1.11$ ), and an aggregate score of $X=13$ (vs. $\bar{x}=15.3, z=-1.15)$ for items $5-8$ related to students' motivation. Teacher L had one of the most positive perceptions of demonstrations' effects on students' performance $(X=20, z=1.86)$ and motivation $(X=20, z=2.35)$. Regardless of their view of the efficacy of lecture demonstrations, however, all interview subjects and correspondents reported regular use of demonstrations as part of their instruction.

Descriptions of the demonstration process included presentations where the teacher, "as the leader of the classroom, display[s] a chemical concept for students" and activities that "[the teacher] or a group of select students conduct[s] for the classroom as whole." The former definition is offered by teacher $\mathrm{H}$, who has five years of chemistry teaching experience and is currently employed to teach more than 300 students each day in an urban public high school, while the latter is the view of teacher E, a four-year veteran teaching in a suburban public school. Such characterizations distinguish lecture demonstration from student-centered activities such as laboratory work, and support the 
definition proposed in Chapter One: that demonstrations are organized and presented by the teacher, with the main body of students acting as an audience.

As part of their definitions of "demonstrations", many interviewees and correspondents offered justifications for the use of lecture demonstrations in chemistry classrooms. Most of the rationales addressed pedagogical issues, such as "to provoke students' thinking", "to clarify specific information", "to connect the theoretical aspects of a lecture to real life", and "to delve deeper into or simply illustrate a topic." Other reasons emphasized the entertaining aspect of demonstrations. Teacher K, a twentythree-year veteran teaching in a suburban public high school, believes that " $[\mathrm{t}] \mathrm{he}$ teacher[s] should have some entertainer in them...this is why I do a 'WOW' demonstration the first day of class...to have them enjoy the class..." while teacher B, with one year of chemistry teaching experience in a religious-affiliated private school, asserts that "[d]emonstrations that are exciting (fire, sound)... are often the ones that help...students become the most engaged and inspired..." Teacher C, who teaches at a suburban public high school and has seventeen years of chemistry teaching experience, believes that "[c]hemistry demonstrations must be smelly, smoky, explosive, or colorful! There is an inherent attention grabbing and entertainment factor in many good chemical demonstrations."

Even where the entertainment value of lecture demonstrations is highlighted, veteran and novice teachers alike tended to stress the instructional aspects of demonstrations. Teacher B intends demonstrations to prompt students to "figure out what happened", particularly when "a surprising result" is observed. Teacher J, a twentyyear veteran teaching at a secular private school, "may sometimes perform 
demonstrations [specifically] to being out...misconceptions" and wishes students to "see the connection to the theoretical"; teacher G (who has taught chemistry for four years in an urban high school) indicates a desire to provide "tangible experiences, so that the course is not abstract." Teacher $\mathrm{K}$, who mentions "rapport"” as a necessary component of an effective demonstration, views the purpose of demonstrations to be "to teach/illustrate an objective in a lesson, to cause the student[s] to think, and to have them talk about what happened with other students." Teacher G states that "I never do a demo just to do it...you have to use the demo at the appropriate place in the lesson or unit", and teacher K agrees, saying that demonstrations "always have a purpose. The purpose is to better the understanding of the world around the student."

Student engagement appears to be an important consideration, apart from any diversion that demonstrations might create. Teacher $\mathrm{H}$ believes that demonstrations must "leav[e] a lasting impression..." and "bring... as many senses into play as possible.", and teacher A, who has taught chemistry for five years at a private religious school in an urban setting, says (twice) that a successful demonstration requires "enthusiasm on behalf of the teacher." Teacher D, with thirty-two years of chemistry teaching experience in a rural public school, bluntly states: “if I can't get their attention...I can't teach them anything." Given the perception that lecture demonstrations increase chemistry students' motivation, the aforementioned opinions are unsurprising, but do indicate the conscious effort on the part of educators to make demonstrations educationally meaningful as well as appealing.

The researcher postulated that some chemistry teachers might use lecture demonstrations in lieu of students' laboratory experiences, and all interviewees and 
correspondents indicated that although laboratory activities were preferable, occasional replacement of lab work with demonstrations was appropriate and necessary. Many of the teachers who answered the extended questionnaire articulated the same reasons for such substitutions: safety concerns that arise when inexperienced or careless individuals handle reactive substances or delicate equipment, and cost considerations where larger classes and less-affluent institutions preclude broader-scale investigations. Teacher B was the only correspondent, however, to propose (albeit with reluctance) another practical reason to employ demonstrations in place of student laboratory work:

I am frequently torn between wanting to show more demonstrations and wanting to do more labs. I think a lot of teachers rely on demos because labs are so time consuming. ...I often too feel drawn to rely on demonstrations when I cannot take prepping or cleaning up another lab.

Other chemistry teachers participating in interviews or correspondence mentioned the opportunity to augment students' laboratory work with demonstrations that address safety procedures or introduce lab skills, using demonstrations in combination with, rather than in lieu of, laboratory investigations.

When asked about their favorite demonstrations to perform, teachers invariably focused on the spectacular, choosing words such as "explosive", "dramatic", and “impressive" and citing students' positive responses. "My favorite ones are also fun, and get a good reaction from students", says teacher G; teacher L, a twenty-two-year veteran teaching in a suburban public high school, favors demonstrations that produce "something that's sensational... a show and tell—something I use to motivate and captivate the kids. ... Whatever is in line for the task of the day-show them what you're doing." Teacher F, who has taught chemistry at a rural public high school for eleven 
years, enjoys the fact that students "can actually see something happening." Once again, student engagement is put forth as the primary reason for performing these demonstrations. Teacher B finds that "students are surprised and engaged", while teacher M, with nine years of chemistry teaching experience in a suburban public high school, emphasizes the benefit of a "discrepant" demonstration outcome, which "generates a lot of discussion, and is absolutely necessary for understanding lots of concepts." Some interviewees and correspondents have performed lecture demonstrations outside the regular classroom, either because of safety concerns (such as those arising from highly exothermic reactions) or to stimulate interest in those not currently enrolled in chemistry courses. Teachers D and E have performed demonstrations for such audiences, with the latter conducting a "very few... for fundraising or for advertising of the subject area..." in these instances, the entertainment aspect is paramount, with instruction reserved for those enrolled in chemistry courses.

Varied opinions were noted regarding concepts effectively and ineffectively addressed via lecture demonstrations. Whereas one correspondent (teacher $\mathbf{M}$ ) indicated that demonstrations related to bonding were particularly effective, another (teacher D) suggested that bonding and molecular geometry were ineffectively demonstrated and "more difficult to do." In this instance, the two may simply be applying different definitions, such that passive observation of ball-and-stick or space-filling schematics would represent a demonstration according to teacher J, but would not qualify as such under teacher D's definition.

Teacher $\mathrm{G}$ addressed the related correspondence questions (5 and 6) quite eloquently, stating that although "I could pick one that I don't have a demo for...I'm sure 
there's someone out there who has come up with a good one for this [topic]....[I]n theory, there aren't any" concepts ineffectively addressed through lecture demonstration. Teacher G particularly emphasizes the use of demonstrations to bring about

a particle-based understanding of the world. Most of the best demos at some level help to crack into that. ...Students need to see stuff... because if you just tell them...they don't believe it, and if you test them on things like this later, they'll put their original beliefs down, because misconceptions are hard to break.

Ultimately, teacher G believes that "there are some ineffective demos, but there are no concepts that don't have any good ways of helping demonstrate them. The goal is student understanding, and anything that improves [understanding] is worth doing."

The effect of increased classroom technology on the implementation and efficacy of lecture demonstrations appears to be a function of the extent to which such technology is available to teachers. Those with access to resources such as classroom computers, Internet connections, and projecting equipment can share recorded images or programmed models to illustrate concepts. As teacher B notes, "I tend to show videos of the more dangerous reactions...I have the ability to show videos of things... which I do not have the [means] available to demonstrate" personally. Teachers G and K concur, with the former stating that "there are several good animations of...processes...that are actually very helpful," and the latter adding that "[b]eing able to video them has changed how to look at them. Slow motion...reactions... give a better look at the finer points." Teacher A observes that "the range of demonstrations... has increased drastically. Now we can watch demos [online]" for processes for which "I don't have the resources to do the demo myself...it has truly changed the dynamics of teaching." 
Not all interviewees and correspondents view technology as necessarily superior to the "live" demonstration. Veteran teacher D states that "[t]here are short demonstration videos [for processes that] can also be done in the classroom," a sentiment supported by teacher L, who describes the demonstration process as involving [s]tuff we use every day-it's nothing high-tech; it's the lowest tech we can find. Kids are still amazed by the simplest things... [b]ecause I haven't employed technology from day one, because I use the simplest of equipment, it hasn't changed what I do at all. Teacher M also feels that technology has not affected her use of demonstrations "at all. I do show computer simulations that are quasi demonstrations, but I don't think those really count [as demonstrations].”

The role of students during demonstrations depends on the amount of control the teacher wishes to assume. Teacher H prefers students to be "active watchers", while others expect students to "participate...[s]ometimes....actually perform the demo once I model it" (teacher C), sometimes for the purpose of educating others - as teacher K indicates, "we have students go to an elementary school and do demonstrations to excite [the elementary students] about science." "I like for them to participate-I think it is more effective..." states teacher D. Regardless, all interviewees and correspondents demand that students be thoughtful observers; teacher B attempts to have "students... uncover the explanation rather than [be told] what happened." Teacher G expects students "[t]o watch, observe, and think about what's going on", while teacher A requests that observers provide "their undivided attention and interest." The demonstrator's role is best articulated by teacher $\mathrm{J}$, who indicates that the instructor is typically "asking students questions about what is being done, what is occurring, what are some 
extensions" to the concepts being demonstrated. Once again, participants in interviews and correspondence reveal their intent to use demonstrations to reinforce ideas, rather than merely producing diversions.

At the end of each extended questionnaire, participants were asked to communicate any additional comments they wished to share regarding classroom demonstrations. Teacher F took the opportunity to warn other chemistry teachers: "[i]f you just show demos for the sake of wowing students without linking...to any content, [demonstrations are] pretty much worthless. I have had colleagues do this and kids did not know what was going on." Teacher D expresses the same idea more succinctly, stating that demonstrations "can be very effective if used correctly." Other correspondents and interviewees were more zealous: teacher $\mathrm{M}$ describes demonstrations as "an integral part of chemistry", and teacher $\mathrm{C}$ believes that "[d]emonstrations are the heart and soul of the chemistry classroom. Next to the 'hands on' of the lab, they are the best and most effective teaching tool. This is what students remember the most."

Whether classroom demonstrations truly lead to increased student performance and motivation is indeterminate, but at least one individual believes that experiencing demonstrations as a student spurred his desire to study chemistry further. Teacher $\mathbf{J}$ states that "[d]emonstrations I saw may have helped me understand the concept, but [most significantly] probably got me excited about chemistry...[p]robably the reason I became interested in chemistry and got me to become a chemistry teacher." Agreeing is Teacher L, who cites his own experiences as a beginning teacher: "[ $\mathrm{t}] \mathrm{he}$ mentors that broke me in made demonstrations an everyday thing... at the beginning of my career, I 
went to a...workshop. High school chemistry teachers were there, showing off their

favorite demonstrations. It made me interested in employing demonstrations", and adds

I would certainly encourage new teachers to attend one of these [demonstration] workshops... it seems that the new generation lacks the interest in performing demonstrations - the first time I saw a demonstration in the classroom, I thought 'wow-I've really got to do this.' I just don't see that any more with new teachers.

Teacher $\mathrm{J}$ is convinced that demonstrations have had a lasting effect on learners: "students move on, graduate, and [when] I cross paths with them, they remember that flame test that I did for them; they may not remember the chemistry, but they remember the demo", and recalls a comment from a specific student, who indicated that lecture demonstrations "“sparked my interest and [inspired] me to delve a little deeper into chemistry...to pursue a career in a chemistry-related field.'”

\section{Research questions}

Survey, correspondence, and interview data clearly indicate that high school chemistry teachers routinely employ classroom demonstrations as part of their instruction (research question 1), with all but one of the participating chemistry teachers indicating current use of lecture demonstrations and with each indicating intent to employ demonstrations in the future. Research questions 2 and 3 ("[d]o high school chemistry teachers perceive students' performance to be improved... and motivation to be enhanced...by the use of classroom demonstrations") are also answered in the affirmative, with $95 \%$ confidence intervals for item scores well above the median scale value representing "no [perceived] effect." 
Research question 4 addressed the possible correlation between chemistry teachers' exposure as students to lecture demonstrations (survey item 9) and their current use of demonstrations (item 10). As previously discussed, frequency values were approximated by the researcher from subjects' self-reported experience. The lack of precision in the recorded values undermines any confidence in the calculated correlation. Despite the questionable nature of the data used to calculate it, the Pearson productmoment correlation was determined for forty-three pairs of data; nine educators had not provided a quantifiable answer to either item 9 or item 10 and their data could not be included in any meaningful comparison. A coefficient of $r=0.513$ was calculated, with a corresponding effect size $r^{2}=0.263$. Gravetter and Wallnau (2007), citing Cohen (1988), state that an effect size (percentage of variance explained) greater than 0.25 represents a large effect, but such a conclusion may not be warranted given the uncertainty in the individual data points.

As teachers' assessments of their own practices are likely to be more accurate than their recollection of their experiences as high school students, the researcher has some confidence in the numerical values reported for teachers' frequency of use of lecture demonstrations. The Pearson correlation was determined between the subjects' self-reported number of demonstrations performed per week (item 10) and their years of chemistry teaching experience (item 13) in order to address research question 5. From a set of forty-seven data pairs (with five teachers not articulating a sufficiently specific frequency of demonstration performance), a correlation coefficient $r=0.252$ was calculated. The low value of $r$, and the correspondingly weak effect size $r^{2}=0.064$, 
indicate little correlation between teachers' years of chemistry teaching experience and frequency with which classroom demonstrations are performed.

Research question 6 posited a relationship between chemistry teachers' degree specialization (item 14) and their use of lecture demonstrations (item 10). The pointbiserial correlation coefficient was calculated to determine the strength of the relationship between the frequency with which each teacher performs demonstrations and whether the teacher holds a degree in chemistry. Thirty-six teachers in the survey group self-reported a major or minor concentration in chemistry or a related field (such as biochemistry or chemical engineering) and received a degree-category score of 1 . The remaining sixteen teachers who indicated degrees in other fields received a degree-category score of 0. After removal of data for the five respondents who had not provided a quantifiable answer describing the number of demonstrations performed per five class days), fortyseven data pairs were available to determine the correlation. A value of $r=0.294$, with an effect size $r^{2}=0.086$, indicates at a maximum a small relationship between chemistry teachers' educational background (presence or absence of a chemistry major or minor) and frequency with which lecture demonstrations are performed.

The absence of any strong correlations found in the data can be traced to two factors: the tendency of nearly all of the survey participants to conduct classroom demonstrations, and the realistic limit to the number of demonstrations that can be performed each week as part of the instructional process. With minimal variation in the frequency with which lecture demonstrations can be performed, and with $73.1 \%$ of survey participants (38 of 52) indicating that they perform demonstrations at least once per ten class meetings, little dependence on educational background, years of chemistry 
teaching experience, or previous exposure to classroom demonstrations should be anticipated.

The minor research question RQ7 ("What best-practice research related to classroom demonstrations guides high school chemistry teachers?") was partially addressed through interviews and correspondence with twelve volunteers, all of whom asserted no familiarity with published research regarding classroom demonstrations. Teacher G, in particular, expressed some doubts about the usefulness of research related to the effectiveness of classroom demonstrations:

I don't keep up with the research anymore, because I've figured out things that work. ...However, I've heard whispers here and there that some people think demos are a waste of time. This is categorically false. Anyone who says that is either not properly using them, or is using demos that have no purpose.

An incontestable negative answer to research question 7 is impossible to obtain through survey or interview data, since those questioned may simply not recall exposure to studies regarding demonstrations. In addition, some interviewees and correspondents clearly misinterpret the publication of specific demonstrations in journals or texts as evidence for research into their pedagogical effectiveness. Still, the absence of specific citations may imply that research related to classroom chemistry demonstrations is either not commonly shared with high school teachers, or that there is a scarcity of such research. The latter possibility is supported by the lack of published studies regarding the extent to which, and the perceived effects of, lecture demonstrations. 


\section{Chapter Five}

\section{Discussion}

\section{Prevalence of demonstrations}

Perhaps the most striking result from the survey was the prevalence of lecture demonstrations in high school chemistry classrooms. Of the fifty-two chemistry teachers who returned completed surveys, fifty-one indicated that they performed demonstrations as part of their instruction. While no specific reason was listed by the single exceptiona first-year teacher holding a mathematics degree_-one might speculate that a lack of previous experience in teaching, and a relative dearth of exposure to chemistry demonstrations and laboratory work, might preclude this individual from including demonstrations to illustrate or introduce concepts. Indeed, this individual's responses to later survey items indicated intent to add demonstrations in subsequent terms (stating a plan to "increase [their use] to once per week"), suggesting that the exclusion of demonstrations was not a deliberate act.

In the absence of a true statistical sample, it would be risky to generalize the results and presume that all chemistry teachers nationwide use demonstrations in their pedagogy. Still, even if one were to assume that all thirty-six of the eighty-nine chemistry teachers who did not return surveys did so because they do not perform lecture demonstrations, it is evident that a substantial majority of surveyed teachers do employ demonstrations as part of classroom instruction. 
Perceived effects

The range of options for the selected-response items $(1-8)$ was limited; respondents were provided only five categories (strongly negative effect, slightly negative effect, no effect, slightly positive effect, strongly positive effect) from which to select. Nevertheless, the results for specific items and within categories were quite revealing. Only one of the fifty-two respondents perceived a negative effect on student performance and motivation as a result of observing lecture demonstrations; all other participants indicated their belief that the use of demonstrations in chemistry classrooms had no worse than a neutral effect. Most significantly, all of the respondents believed that observing chemistry demonstrations produced a slightly positive to strongly positive effect on students' understanding of concepts (item 4).

For each survey participant, the scores of items $1-4$ were totaled to produce a performance category aggregate. As each item score was an integer between 1 and 5 inclusive, aggregates thus obtained had a minimum possible value of 4 and a maximum value of 20. The mean of aggregate scores for performance-related survey items $1-4$ was $\bar{x}=16.9( \pm 0.457, \alpha=0.05, n=52)$, with a standard deviation $s=1.68$. An aggregate score for items $5-8$, related to student motivation, was also determined for each participant; the mean of aggregate scores for motivation-related survey items $5-8$ was $\bar{x}=15.3( \pm 0.542, \alpha=0.05, n=52)$, with a standard deviation $s=2.00$.

Survey participants tended to view the effect of lecture demonstrations on students' performance to be somewhat greater than the effect on motivation. The confidence intervals of the mean aggregate scores for performance (items $1-4$ ) and for 
motivation (items $5-8$ ) do not overlap at the $\alpha=0.05$ level, indicating that the category means are significantly different (Knezevic, 2008). The $\alpha=0.05$ confidence intervals of the mean scores for lab performance (item 2: $\bar{x}=4.27 \pm 0.153$ ) and lab-related motivation (item 6: $\bar{x}=3.83 \pm 0.192$ ) do not overlap at the $\alpha=0.05$ level; likewise, there is no overlap in the $\alpha=0.05$ confidence intervals of the mean scores for exam performance (item 3: $\bar{x}=4.10 \pm 0.155$ ) and exam-related motivation (item 7: $\bar{x}=3.60 \pm$ 0.180). In both categories, the difference in the mean scores for the related items is statistically significant (Knezevic, 2008). The significant difference in the means suggests that the survey participants considered motivational effects at least somewhat independently of performance effects, and so did not automatically select the same scores for items related to motivation as were assigned to items related to performance.

While failure of confidence intervals to overlap indicates a statistically significant difference between means, no conclusion about differences of means can be drawn when confidence intervals do overlap (Knezevic, 2008). The confidence intervals of the mean scores for item 1 (homework performance, for which $\bar{x}=3.90 \pm 0.196$ ) and item 5 (homework-related motivation, where $\bar{x}=3.54 \pm 0.182$ ) overlap slightly, and one cannot determine whether differences of these mean values is significant.

Item analysis

Within the category of survey questions related to students' performance, the largest mean and smallest standard deviation were recorded for item 4 , the scores for which measured teachers' opinions regarding the effect on students' understanding of 
concepts. The very high mean value (4.60 on a five-point scale), and the absence of any score less than 4 (which represented a "slightly positive effect) indicates that teachers view the understanding of concepts to be the primary benefit to the learner resulting from the observation of lecture demonstrations in chemistry classes. Mean scores for other items related to student performance (performance on homework assignments, in laboratory work, and on exams were also positive, although a number of scores representing the absence of an effect were recorded for these items, particularly for item 1 (effect on homework performance, for which 13 of 52 , or $25.0 \%$, perceived demonstrations to produce no change in students' performance on homework assignments).

In the category of motivation, the largest mean and smallest standard deviation were recorded for item 8 , related to students' interest in future chemistry courses; 48 of $52(92.3 \%)$ of survey participants believed that classroom demonstrations increased students' motivation to enroll in additional courses (at or beyond the current institution) related to the subject. As was the case in the performance category, motivational effects were perceived to be least evident for completion of homework assignments.

For item 9, each participant was asked to state the number of times per week-per five class days - that their chemistry teacher had performed demonstrations; it item 10, respondents were asked to indicate the number of times per week they currently perform demonstrations. Forty-three of fifty-two $(82.7 \%)$ of those surveyed provided numerical answers to both items; where a range (such as " $1-2$ " demonstrations performed per week) was expressed, the researcher attempted to quantify a value within the middle of the specified range. In cases where a nonspecific value was expressed (e.g. "about twice 
per semester"), the researcher used a twenty-week term (or a four-week month) to calculate an approximate number to record. Although the remaining nine participants did supply answers to items 9 and 10, their responses were not reported in easily-quantifiable terms (e.g. "regularly, but don't remember how often"), and the corresponding database entries were left blank. Of the forty-three chemistry teachers reporting adequatelyspecific values for each of items 9 and 10, ten participants (23.3\%) indicated that they perform demonstrations for their current classes less often than their own high school chemistry teachers did, while fourteen $(32.6 \%)$ claimed to perform demonstrations with the same frequency as they witnessed as students. Given that recollection of their own high school experiences are not likely to be highly reliable, and that most responses were nonspecific, the researcher was required to estimate the frequency values from the ranges stated, and any further statistical comparison of the resulting data would be dubious.

\section{Incongruities within responses}

Interviewees and correspondents all perform demonstrations routinely. Of

particular note is teacher $\mathrm{K}$, who, despite being the most neutral of all who completed the extended questionnaire, performs an average of three demonstrations over each five class meetings - substantially more than the reported mean weekly demonstration frequency $(\bar{x}=1.41, z=1.47)$. Teacher $\mathrm{K}$ clearly considers demonstrations to be important to "teach/ illustrate an objective in a lesson, [and] to cause the student[s] to think...I do not do demonstrations just to do them." The apparent difference between teacher K's comments in structured correspondence and the responses selected in the quantitative portion of the survey might only seem discrepant because of the uniformly positive view 
of demonstrations that survey participants express; while none of his responses indicated that demonstrations produce a "strongly positive effect", teacher K believes that students' performance on laboratory exercises and exams, understanding of concepts, and motivation to study chemistry further are improved by witnessing lecture demonstrations - a view consistent with the overall findings of the survey. Any difference between the perceptions of teacher $\mathrm{K}$ and teacher $\mathrm{L}$ (the interviewee expressing the most positive perception of the effectiveness of demonstrations on students' motivation and performance) may simply reflect the limitations of the response categories offered - the distinction between "slight" and "strong" effects is individual and consequently subjective.

\section{Discussion of research questions}

Research question 1: Do high school chemistry teachers routinely employ classroom demonstrations as part of their instruction?

Survey data and responses to the extended questionnaire indicate widespread use of lecture demonstrations to supplement chemistry instruction. All except one of the chemistry teachers who returned the complete survey instrument (51 of 52) indicated current use of classroom demonstrations, and all (52 of 52) plan to incorporate demonstrations in the future. Even if none of the teachers who did not return the survey perform demonstrations, nearly $60 \%$ (53 of 89) of the surveyed population use lecture demonstrations routinely in their instruction.

Research question 2: Do high school chemistry teachers perceive students' performance to be improved by the use of classroom demonstrations? 
Thirty-eight of fifty-two chemistry teachers surveyed believed students' homework performance to be improved by the use of classroom demonstrations (survey item 1). Forty-nine of the fifty-two teachers perceived students' laboratory work to be improved as a result of experiencing demonstrations (survey item 2). Forty-eight of the chemistry teachers perceived demonstrations to produce a positive effect on students exam scores (survey item 3), and all fifty-two of the survey respondents believed students' understanding of chemistry concepts (item 4) to be enhanced by the use of lecture demonstrations. Only one respondent suggested a deleterious effect on student performance, assigning a score of 2 ("slightly negative effect") to both homework and exam performance. Whether these scores truly represent this individual's view is unclear; the same teacher intends to increase the number of demonstrations performed, suggesting a positive view of the effects of lecture demonstrations despite the negative opinion expressed in the survey, and may have misinterpreted the Likert scale options. The aforementioned teacher was unavailable for follow-up contact despite numerous attempts to obtain clarification.

Research question 3: Do high school chemistry teachers perceive students' motivation to be enhanced by the use of classroom demonstrations?

Twenty-three of fifty-two chemistry teachers surveyed believed lecture demonstrations to have a positive effect on students' motivation to perform well on homework assignments (survey item 5), with the remaining twenty-nine perceiving neither a positive or a negative effect. Positive effects on students' motivation to perform well in laboratory exercises (item 6) and on exams (item 7) were perceived by thirty-four and twenty-eight of the fifty-two teachers, respectively; the same individual who 
suggested negative effects on students' homework and exam performance also observed a slightly negative effect on students' motivation to succeed on exams. Forty-eight of the fifty-two chemistry teachers believed lecture demonstrations to improve students' motivation to study the subject further.

Research question 4: Is there a correlation between chemistry teachers' exposure as students to lecture demonstrations and their current use of classroom demonstrations?

Forty-three of the fifty-two surveyed chemistry teachers stated both the frequency with which they currently perform lecture demonstrations and the frequency with which they viewed such demonstrations as students. Although a Pearson product-moment correlation coefficient of $r=0.513$ was calculated (with an effect size $r^{2}=0.263$ ), the self-reported frequency values were approximated, and the correlation is questionable.

Research question 5: Is there a correlation between teachers' years of chemistry teaching experience and their use of classroom demonstrations?

The Pearson correlation between teachers' self-reported frequency with which classroom demonstrations are employed and their years of chemistry teaching experience was determined from forty-seven pairs of data (five teachers did not indicate a specific frequency of demonstration performance). A correlation coefficient of $r=0.252$ (with corresponding effect size $r^{2}=0.064$ ) shows little relationship between participants' years of chemistry teaching experience and the frequency of their use of demonstrations.

Research question 6: Is there a correlation between chemistry teachers' academic preparation (chemistry vs. "non-chemistry" degree) and their use of classroom demonstrations? 
A point-biserial coefficient was calculated to determine any correlation between chemistry teachers' degree preparation (chemistry or non-chemistry specialization) and their reported frequency with which lecture demonstrations are employed. Forty-seven data pairs (excluding those educators who did not report a specific frequency of use of demonstrations) were used to determine the correlation coefficient $r=0.294$ and effect size $r^{2}=0.086$, indicating a weak relationship between degree specialization and the frequency with which demonstrations are employed.

Research question 7: What best-practice research related to classroom demonstrations guides high school chemistry teachers?

None of the twelve participants in the extended questionnaire (via interview or structured correspondence) expressed any familiarity with published research related to classroom demonstrations; the dearth of studies related to the extent to which demonstrations are performed may account for educators' lack of exposure to relevant research. 


\section{Chapter Six}

\section{Conclusion and recommendations}

\section{Summary}

Eighty-nine chemistry teachers randomly selected from a nationwide database of high schools were contacted for inclusion in the research study. Fifty-three of the eightynine returned completed surveys, with one of the fifty-three indicating an assignment teaching physics, rather than chemistry. Twelve survey participants completed extended questionnaires (three through telephone interviews, and nine via email correspondence) describing their experiences with, and rationales for, employing lecture demonstrations.

Quantitative survey data, along with qualitative data from surveys, structured correspondence, and interviews, indicated that the use of lecture demonstrations to supplement instruction in chemistry classrooms is nearly universal. Survey participants, correspondents, and interviewees expressed their belief that demonstrations improve students' performance on practice assignments, laboratory investigations, and exams, as well as enhancing students' understanding of concepts.

Students' motivation to perform well on assignments, laboratory exercises, and exams, and to enroll in further coursework related to chemistry, was also perceived to be improved by the usage of lecture demonstrations. The effect on motivation was perceived to be significantly less than the effect on performance. No correlations were observed between teachers' prior exposure to lecture demonstrations as students and their current use of demonstrations, between teachers' years of chemistry teaching experience and the frequency with which they perform lecture demonstrations, or between degree 
specialization (chemistry vs. non-chemistry) and the frequency of use of demonstrations. Little familiarity with published research related to the effectiveness of lecture demonstrations was indicated.

\section{Limitations of the study}

The scope of the study was restricted to a small percentage of high-school chemistry teachers in the United States. Of the estimated 30,000-40,000 high school chemistry teachers in the nation (The High School Chemistry Teacher, 2009), less than one percent (three hundred) were identified for possible inclusion, and only eighty-nine were contacted, with fifty-three of the eighty-nine (59.6\%) returning surveys. Although great attention was given to randomizing the selection process, and even though the responses did not appear to favor particular demographics, it would be a mistake to presume that the respondents are representative of the entire population of chemistry teachers or to generalize the results.

The desire to restrict the data-collection phase to a single school term (the spring semester of 2011), so that years of teaching experience and current teaching assignments would be accurately reflected, necessarily limited the duration of the research project and the number of teachers surveyed. The significant demands on classroom teachers' time required perseverance on the part of the researcher, and patience and understanding from the participants.

The research study was also limited to queries of teachers' perceptions, and did not attempt to validate, using controlled experiments and measurable data, the opinions 
thus expressed. Results, then, are simply a summary of participants' beliefs, and indicate nothing about genuine effects on students' performance and motivation.

Finally, a response rate of less than one hundred percent, coupled with the nearunanimity of opinion, may indicate that only those most passionate about the use of lecture demonstrations chose to participate, while those indifferent or opposed to the usage of demonstrations declined to return the survey questionnaire. A follow-up contact might reveal the reasons why non-participants elected not to return the completed survey, but such contacts were not made as part of the study.

\section{Recommendations for future research}

Follow-up contacts to determine reasons for non-participation may reveal whether individuals who chose not to return surveys did so because of a particular bias against the use of lecture demonstrations. A broader study, involving a much larger sample of chemistry teachers in the United States, may produce findings that differ from those obtained herein, although if care is not taken to control for teacher mobility and changing years of experience, observed correlations would be suspect, and self-reported behaviors (e.g. frequency with which lecture demonstrations are currently performed) may be altered in unpredictable ways. Additional research might also be conducted, using interview and correspondence data from the current study to refine the survey instrument in order to reveal more about teachers' perceptions regarding the effectiveness of demonstrations on students' performance and motivation.

A quantitative study of learning gains would indicate any congruity between teachers' perceptions and actual student performance. Such research, which would 
require pre- and post-testing of control and experimental groups, was outside the scope of this investigation. Accordingly, the effectiveness of lecture demonstrations on students' motivation and performance on learning tasks remains largely unproven, with anecdotal data gleaned from reporting teachers' personal experiences the primary support for the value of demonstrations in the chemistry classroom. 


\section{References}

Baddock, M. \& Bucat, R. (2008). Effectiveness of a classroom chemistry demonstration using the cognitive conflict strategy. International Journal of Science Education. 30(8), 1115-1128.

Beall, H. (1996). Report on the WPI Conference "Demonstrations as a teaching tool in chemistry: Pro and con." Journal of Chemical Education. 73(7), 641-642.

Bent, H. A. \& Bent, H. E. (1980). What do I remember? Journal of Chemical Education. 57, 609.

Buncick, M.C., Betts, P.G., \& Horgan, D.D. (2001). Using demonstrations as a contextual road map: enhancing course continuity and promoting active engagement in introductory college physics. International Journal of Science Education. 23(12), 1237-1255.

Chemistry Program Review (2008). Retrieved January 30, 2011, from Inver Hills Community College Web site: http://www.inverhills.edu/About/pdfs/ProgramReview07-08/0708Chemistry.pdf

Clermont, C.P., Krajcik, J.S., \& Borko, H. (1993). Comparative study of the pedagogical content knowledge of experience and novice chemical demonstrators. Journal of Research in Science Teaching. 30(1), 21-43.

Clermont, C.P., Borko, H., \& Krajcik, J.S. (1994). Comparative study of the pedagogical content knowledge of experience and novice chemical demonstrators. Journal of Research in Science Teaching. 31(4), 419-441. 
Creswell, J.W. (2007). Qualitative inquiry and research design: Choosing among five approaches. Thousand Oaks, CA: Sage Publications.

Creswell, J.W. \& Plano Clark, V. (2007). Designing and Conducting Mixed Methods Research. Thousand Oaks, CA: Sage Publications, Inc.

Crouch, C., Fagen, A., Callan, J.P., \& Mazur, E. (2004). Classroom demonstrations: Learning tools or entertainment? American Journal of Physics. 72(6), 835-838.

Denzin, N. (ed.) (2006). Sociological methods: a sourcebook. New Brunswick, NS: Aldine Transaction.

Fagen, A. (2003). Assessing and enhancing the introductory science course in physics and biology: Peer instruction, classroom demonstrations, and genetics vocabulary. Cambridge, MA: Harvard University.

Faraday, M. (1904). The chemical history of a candle: a course of lectures. London: Hazell, Watson, and Viney.

Glasson, G.E. (1989). The effects of hands-on and teacher demonstration laboratory methods on science achievement in relation to reasoning ability and prior knowledge. Journal of Research in Science Teaching. 26(2), 121-131.

Gravetter, F. \& Wallnau, L. (2007). Statistics for the behavioral sciences, $7^{\text {th }}$ edition. Belmont, CA: Thomson Wadsworth.

Gregory, A. (2008). Optimal economic design of mail surveys: Influences on response rates and the impact of responses to a second mailing. Retrieved April 17, 2011 from Public Opinion Quarterly Web site: http://krex.k-state.edu/dspace/bitstream/2097/815/1/AlexandraGregory2008.pdf 
Haddock, E., Naylor, R., Rowlinson, I., Pendleton, V., Woodward, C., \& Craig, P. (2008). Motivational activities to support key Stage 3 and Stage 4 science. Retrieved January 17, 2010, from Scribd web site: http://www.scribd.com/doc/4663410/Motivation-Motivating-Activities-BookletTeacher-Notes.

Hatch, J.A. (2002). Doing qualitative research in education settings. Albany, NY: State University of New York Press.

Hiles, D.R. (1997). Paradigms lost—paradigms regained. Presented at 18th International Human Science Research Conference, Sheffield, UK, July 26 - 29, 1999. Retrieved October 31, 2009 from http://www.psy.dmu.ac.uk/drhiles/Paradigms\%20Lost.htm.

House, J. D. (2000). Relationships between instructional activities and science achievement of adolescent students in Hong Kong: Findings from the Third International Mathematics and Science Study (TIMSS). International Journal of Instructional Media. 27(3), 275-288.

Ivankova, N., Creswell, J., \& Stick, S. (2006). Using mixed methods sequential explanatory design: From theory to practice. Field Methods, 18(1), 3-20.

Jensen, W. B. (1991). To demonstrate the truths of "Chymystry". Bulletin for the History of Chemistry. 10. 3-15.

Kaplowitz, M. D., Hadlock, T.D., \& Levine, R. (2004). A comparison of Web and mail survey response rates. Retrieved February 7, 2010 from Public Opinion Quarterly Web site: http://poq.oxfordjournals.org/cgi/content/full/68/1/94. 
Kauffman, G. B. (1996). Lecture demonstrations, past and present. The Chemical Educator. 1(5). 1-33.

Knezevic, A. (2008). StatNews \#73: Overlapping confidence intervals and statistical significance. Retrieved April 23, 2011, from Cornell University Statistical Consulting Unit Web site: http://www.cscu.cornell.edu/news/statnews/stnews73.pdf

Lynch, M. J. \& Zenchak, J. J. (2002). Use of scientific inquiry to explain counterintuitive observations. Paper presented at the Annual Conference of the Association for the Education of Teachers in Science, Charlotte, NC.

Meyer, L. S., Schmidt, S., Nozawa, F., Panee, D., \& Kisler, M. (2003). Using demonstrations to promote student comprehension in chemistry. Journal of Chemical Education. 80(4), 431-435.

Milne, C. \& Otieno, T. (2007). Understanding engagement: Science demonstrations and emotional energy. Science Education. 91(4), 523-553.

Morse, J. M., Barrett, M., Mayan, M., Olson, K., \& Spiers, J. (2002). Verification strategies for establishing reliability and validity in qualitative research. International Journal of Qualitative Methods 1(2), Article 2. Retrieved October 31, 2009, from http://www.ualberta.ca/ ijqm/.

Pierce, D. T., \& Pierce, T. W. (2007). Effective use of demonstration assessments in the classroom relative to laboratory topics. Journal of Chemical Education. 84(7), 1150-1155.

Plano Clark, V. \& Creswell, J. (2008). The Mixed Methods Reader. Thousand Oaks, CA: Sage Publications, Inc. 
Porter, S. R., \& Whitcomb, M. E. (2007). Mixed mode contacts in Web surveys: Paper is not necessarily better. Public Opinion Quarterly. 71(4), 635-648.

Ramette, R. W. (1980). Exocharmic reactions. Journal of Chemical Education. 57(1), 68-69.

Roadruck, M. D. (1993). Chemical demonstrations: Learning theories suggest caution. Journal of Chemical Education. 70(12), 1025-1028.

Roth, W-M., McRobbie, C.J., Lucas, K.B., Boutonné, S. (1997). Why may students fail to learn from demonstrations? A social practice perspective on learning in physics. Journal of Research in Science Teaching. 34(5), 509-533.

Schraw, G. \& Lehman, S. (2001). Situational interest: A review of the literature and directions for future research. Educational Psychology Review. 13(1), 23-52.

Schrempp, C. (2008). Bangs, flashes, and explosions. Retrieved January 17, 2010 from ExploScience Web site: http://exploscience.com/Book.html

Shakhashiri, B. Z. (1983, 1985, 1989, 1992, 2011a). Chemical demonstrations: $a$ handbook for teachers of chemistry, volumes 1-5. Madison, WI: University of Wisconsin Press.

Shakhashiri, B. Z. (2011b). "Address to the Colorado Local Section of the American Chemical Society.” Colorado ACS Awards. Golden, CO. 18 April 2011. Sharpen existing skills and develop new teaching techniques. (2011). Retrieved January 29, 2011, from Flinn Scientific, Inc. Web site: http://elearning.flinnsci.com/CourseDescriptions.aspx 
Shmaefsky, B. R. (2004). Favorite demonstrations for college science: an NSTA Press Journals collection. Arlington VA: National Science Teachers Association Press.

Shmaefsky, B. R. (2005). MOS: The critical elements of doing effective classroom demonstrations. Journal of College Science Teaching. 35(3), 44-45.

Silberman, R. G. (1983). A General Chemistry demonstration: Student observations and explanations. Journal of Chemical Education. 60(11), 996-997.

Spangler, S. (2010). Hands-on science toys \& easy science experiments. Retrieved January 17, 2010 from Steve Spangler Science web site: http://www.stevespanglerscience.com/

Sprott, J. C. (2006). Physics demonstrations: A sourcebook for teachers of physics. Madison, WI: University of Wisconsin Press.

Stake, R. E. (1995). The art of case study research. Thousand Oaks, CA: Sage Publications.

Swanson, E. (1999). Chemical demonstrations in the classroom. Retrieved January 23, 2010 from Bradley University Web site: http://bradley.bradley.edu/ campbell/elishapaper.htm

Taylor, C. A. (1988). The art and science of lecture demonstration. New York: Taylor \& Francis Group. 
The High School Chemistry Teacher: Status and Outlook (2009). From Strengthening high school chemistry education through teacher outreach programs: A workshop summary to the Chemical Sciences Roundtable. Washington, DC: National Academies Press. Retrieved May 1, 2011 from National Center for Biotechnology Information Web site: http://www.ncbi.nlm.nih.gov/books/NBK26411/

The Mission of the YSU Chemistry Department (2011). Retrieved January 30, 2011, from the Youngstown State University STEM Web site: http://web.ysu.edu/stem/chemistry

Waldman, A. S., Schechinger, L., \& Nowick, J. S. (1996). A coordinated chemistry outreach program for thousands of high school students. Journal of Chemical Education. 73(8), 762-764. 


\section{Appendix A: Informed Consent Letter-Survey}

\section{Nebibrastio \\ Lincoln}

1 September 2010

DAVID W. BROOKS

\section{Dear $x x x x x x x x x x x x x$}

As part of my doctoral coursework, I am conducting a survey-based research project to determine the extent to which classroom demonstrations are used in science classes. The working title of the project is "Extensiveness and Perceptions of Lecture Demonstrations in the High School Chemistry Classroom." You have been selected for possible inclusion in the study because you may have experience with classroom demonstrations in your teaching. It is anticipated that research of this type will lead to improvements in the presentation and effectiveness of classroom demonstrations. Your assistance in the data collection is appreciated.

If you are willing to participate, you will be asked to take part in a telephone- or emailbased survey that should require no more than ten minutes to complete. At no time will identifying personal information be reported, and data (including individual survey responses) will be stored on password- and biometric-secured computers. When specific individuals' responses are cited, confidentiality of all participants will be maintained through the use of pseudonyms for participants and institutions. You are free to decide not to participate in this study. You may also withdraw at any time without harming your relationship with the researchers, the University of Nebraska-Lincoln, or your school. Participants may elect to leave the project at any time; responses from those who leave the project will not be used. There are no known risks associated with participation in this research. A donation to a disaster-relief organization, in the amount of ten dollars, will be made for each individual who completes the survey.

Participants in research studies such as this have the right to ask questions and to have those questions answered. You may contact the lead researcher, Daniel Price, at any time, via telephone at 7202326737 or via email at Daniel.Price@huskers.unl.edu. You may also contact the project supervisor, Dr. David Brooks, via telephone at 4024722018 or via email at dbrooks@unlserve.unl.edu. Should you have questions about your rights as a study participant, you may also contact the University of Nebraska-Lincoln Institutional Review Board at 4024726965 .

We value your opinions and experience, and look forward to your participation in this research study.

--Daniel Price, graduate student and lead researcher, University of Nebraska 


\section{Appendix B: Survey Questionnaire (reformatted from full-width "landscape" version)}

Survey of perceived effects of classroom demonstration on student performance and motivation

For the following four questions, pertaining to student performance, please select the most appropriate response from the options given, based on your perception. Lower numbers indicate more negative effects, while higher numbers indicate more positive effects.

1. How are students' homework assignment scores affected by viewing classroom demonstrations?

1 - strongly negative effect

$2-$ slightly negative effect $\quad 3-$ no effect

4 - slightly positive effect

5 - strongly positive effect

2. How are students' lab assignment scores affected by viewing classroom demonstrations?

1 - strongly negative effect $\quad 2$ - slightly negative effect 3 -no effect

4 - slightly positive effect $\quad 5$ - strongly positive effect

3. How are students' exam scores affected by viewing classroom demonstrations?

$1-$ strongly negative effect $\quad 2$ - slightly negative effect $\quad 3$ - no effect

4 - slightly positive effect $\quad 5$ - strongly positive effect

4. How is students' understanding of chemistry concepts affected by viewing classroom demonstrations?

1 - strongly negative effect $\quad 2$ - slightly negative effect $\quad 3$ - no effect

4 - slightly positive effect $\quad 5$ - strongly positive effect

For the next four questions, pertaining to student motivation, please select the most appropriate response from the options given.

5. How is students' motivation to perform well on homework assignments affected by viewing classroom demonstrations?

1 - strongly negative effect

2 - slightly negative effect

3 - no effect

4 - slightly positive effect

5 - strongly positive effect

6. How is students' motivation to perform well on lab assignments affected by viewing classroom demonstrations?

1 - strongly negative effect

2 - slightly negative effect

3 - no effect

4 - slightly positive effect

5 - strongly positive effect 
7. How is students' motivation to perform well on exams affected by viewing classroom demonstrations?
1 - strongly negative effect
2 - slightly negative effect
$3-$ no effect
4 - slightly positive effect
5 - strongly positive effect

8. How is students' motivation to study this subject further (additional courses at this school or beyond) affected by viewing classroom demonstrations?
1 - strongly negative effect
2 - slightly negative effect
$3-$ no effect
4 - slightly positive effect
5 - strongly positive effect

Please provide brief answers to each of the following questions:

9. In your experience as a student, approximately how many times per week (per five class days), on average, did your chemistry instructor perform classroom demonstrations?

10. How many times per week (per five class days), as a teacher of chemistry, do you perform classroom demonstrations?

11. To what extent do you plan to change the number of classroom demonstrations that you perform in the classes that you teach?

Please provide brief answers to each of the following questions:

12. How many years of experience do you have in teaching science?

13. How many years of experience do you have in teaching chemistry (including Conceptual, Honors, and AP-level courses)?

14. In what specific area(s) is/are your degree specialization(s)? 
15. If you are willing to participate in an interview related to your experiences with and opinions regarding classroom demonstrations, please provide your email address (or other preferred contact information). A charitable donation to a disaster relief organization will be made on behalf of each individual who completes the interview process. All personally identifying information will be kept confidential. 


\section{Appendix C: Survey Questionnaire Item Abstract Table}

Questionnaire Abstract: Research Questions

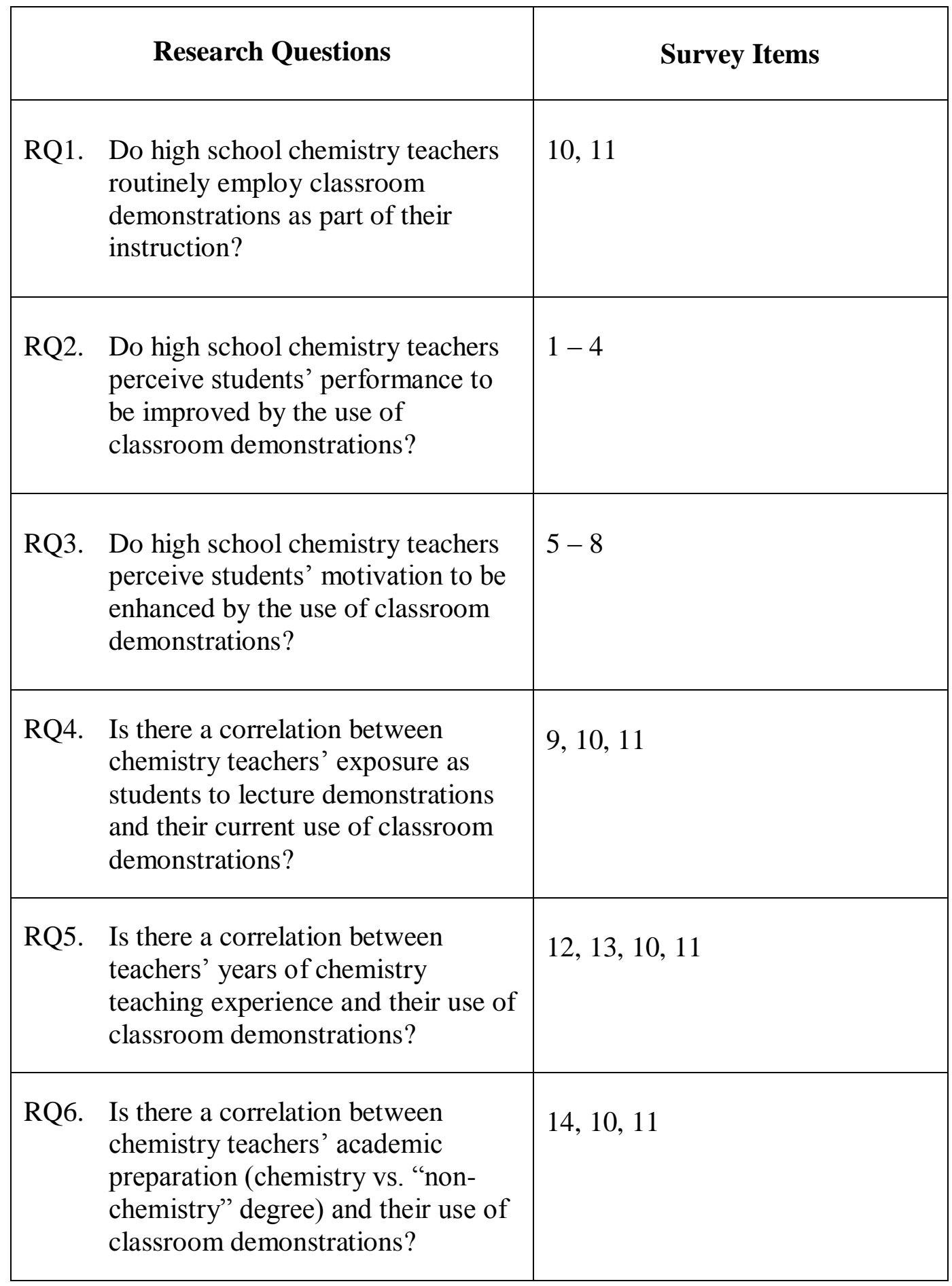




\section{Appendix D: Informed Consent Letter-Extended Questionnaire}

\section{Nebibisile \\ Lincoln}

1 September 2010

DAVID W. BROOKS

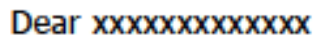

As part of my doctoral coursework, I am conducting an interview-based research project to determine the extent to which classroom demonstrations are used in science classes. The working title of the project is "Extensiveness and Perceptions of Lecture Demonstrations in the High School Chemistry Classroom." You have been selected for possible inclusion in the study because you may have experience with classroom demonstrations in your teaching. It is anticipated that research of this type will lead to improvements in the presentation and effectiveness of classroom demonstrations. Your assistance in the data collection is appreciated.

If you are willing to participate, you will be asked to take part in an email interview that should require no more than thirty minutes to complete. At no time will identifying personal information be reported, and data (including individual survey responses) will be stored on password- and biometric-secured computers. When specific individuals' responses are cited, confidentiality of all participants will be maintained through the use of pseudonyms for participants and institutions. You are free to decide not to participate in this study. You may also withdraw at any time without harming your relationship with the researchers, the University of Nebraska-Lincoln, or your school. Participants may elect to leave the project at any time; responses from those who leave the project will not be used. There are no known risks associated with participation in this research. A donation to a disaster-relief organization, in the amount of twenty dollars, will be made for each individual who completes the interview process.

Participants in research studies such as this have the right to ask questions and to have those questions answered. You may contact the lead researcher, Daniel Price, at any time, via telephone at 7202326737 or via email at Daniel.Price@huskers.unl.edu. You may also contact the project supervisor, Dr. David Brooks, via telephone at 4024722018 or via email at dbrooks@unlserve.unl.edu. Should you have questions about your rights as a study participant, you may also contact the University of Nebraska-Lincoln Institutional Review Board at 4024726965 .

We value your opinions and experience, and look forward to your participation in this research study.

--Daniel Price, graduate student and lead researcher, University of Nebraska

Professor of Chemistry Education / Department of Teaching. Learning, and Teacher Education / dbrooks 1 @inl.edu 18 Henzllk Hall, Lincoln, NE 68588-0355 (402) 472-2018 / FAX: (402) 472-8317 http://dwb.unl.edu 


\section{Appendix E: Extended Questionnaire}

Initial questions (to be supplemented with follow-up items based on interviewees' or correspondents' initial responses):

1. Briefly define "demonstration", and describe how you would conduct a typical classroom demonstration. Include, in your description, activities before, during, and after the demonstration.

2. What qualities, behaviors, equipment, and materials are necessary for a successful demonstration?

3. Please list, in decreasing order of importance (i.e. from most to least important), the purposes of classroom demonstrations.

4. Do you have particular demonstrations that you would consider "favorites"? What characterizes these as "favorites"?

5. Which important curriculum concepts are most effectively addressed using classroom demonstrations?

6. Which curriculum concepts are ineffectively addressed using classroom demonstrations?

7. When should demonstrations be used to substitute for students' own laboratory experiences?

8. Which demonstrations do you perform (or have you experienced) outside the regular classroom? If so, for what purpose are the demonstrations employed?

9. How have changes in classroom technology affected the range and type of demonstrations that you perform?

10. What is the students' role in classroom demonstrations?

11. With what published research related to classroom demonstrations are you familiar? 
Appendix F: Extended Questionnaire Item Abstract Table

Questionnaire Abstract: Research Questions

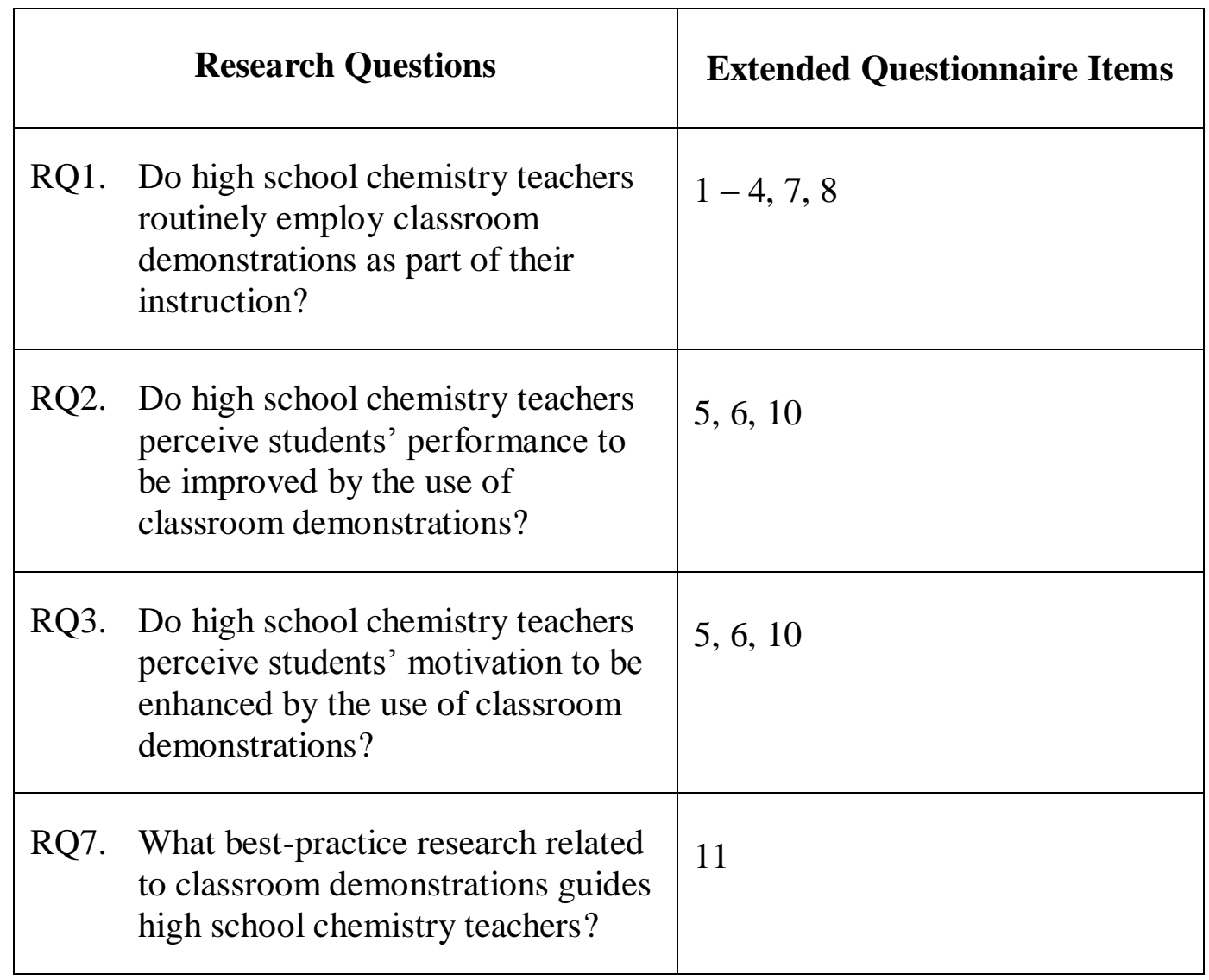




\section{Appendix G: Survey Responses-Summary Tables}

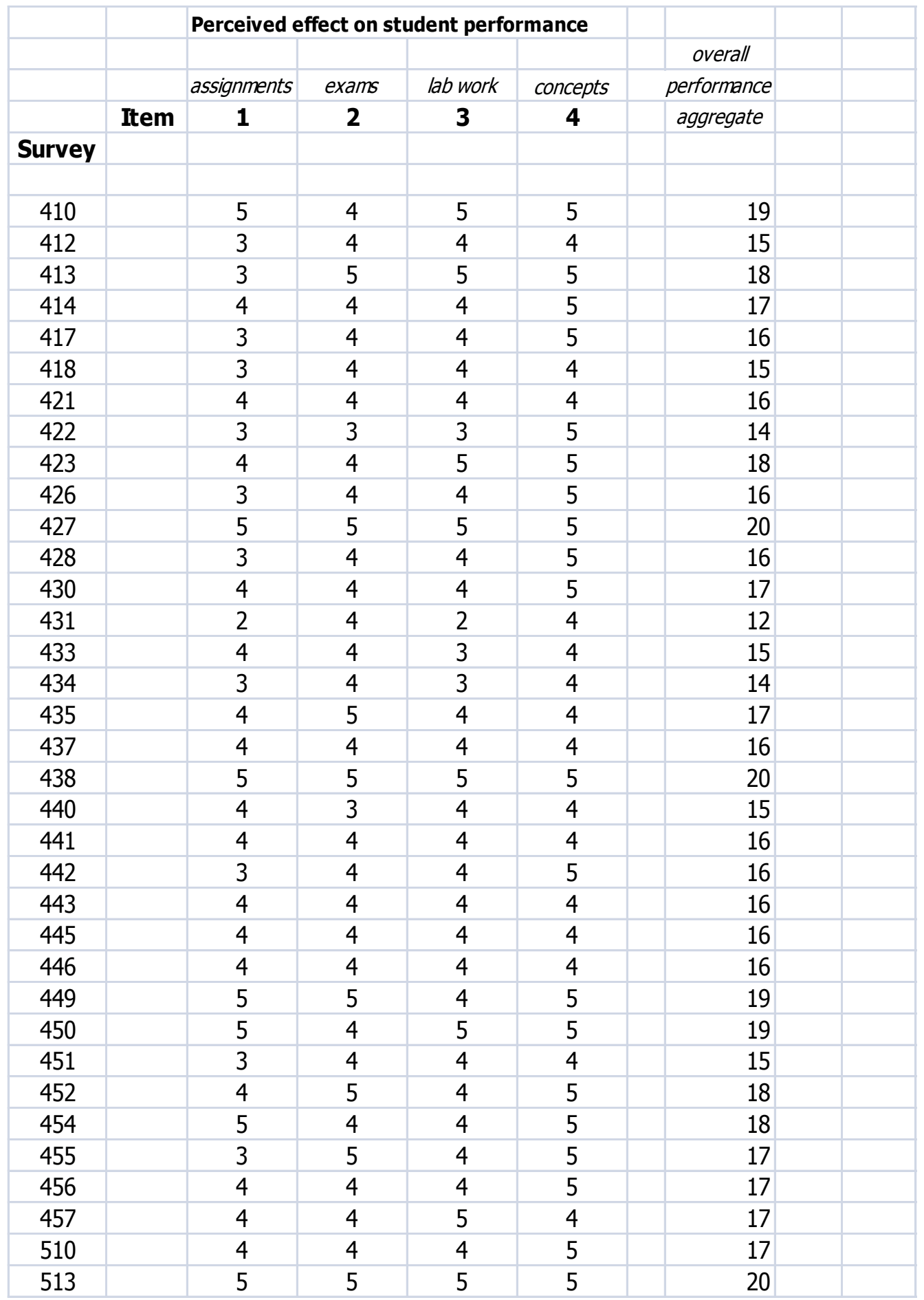




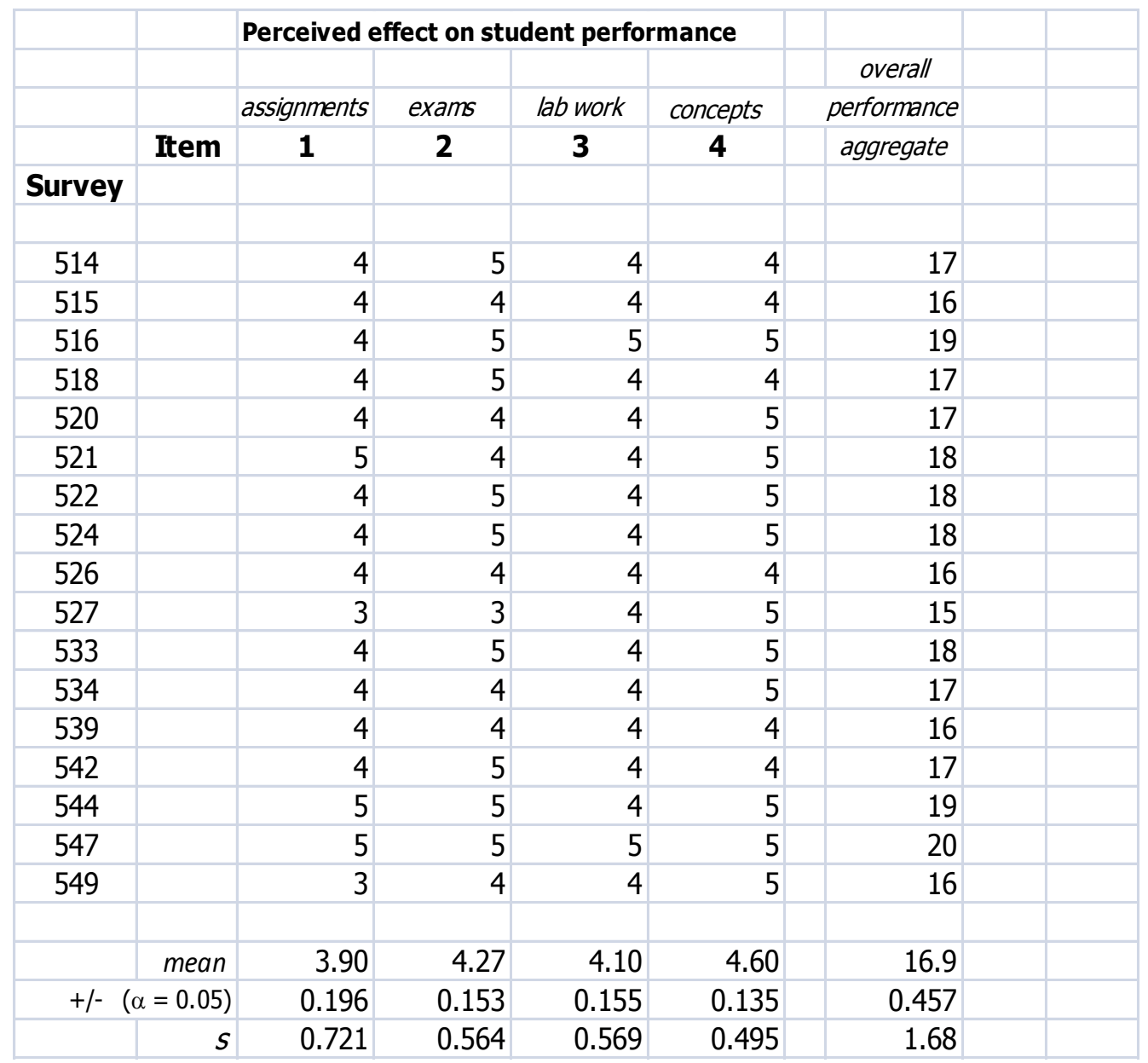




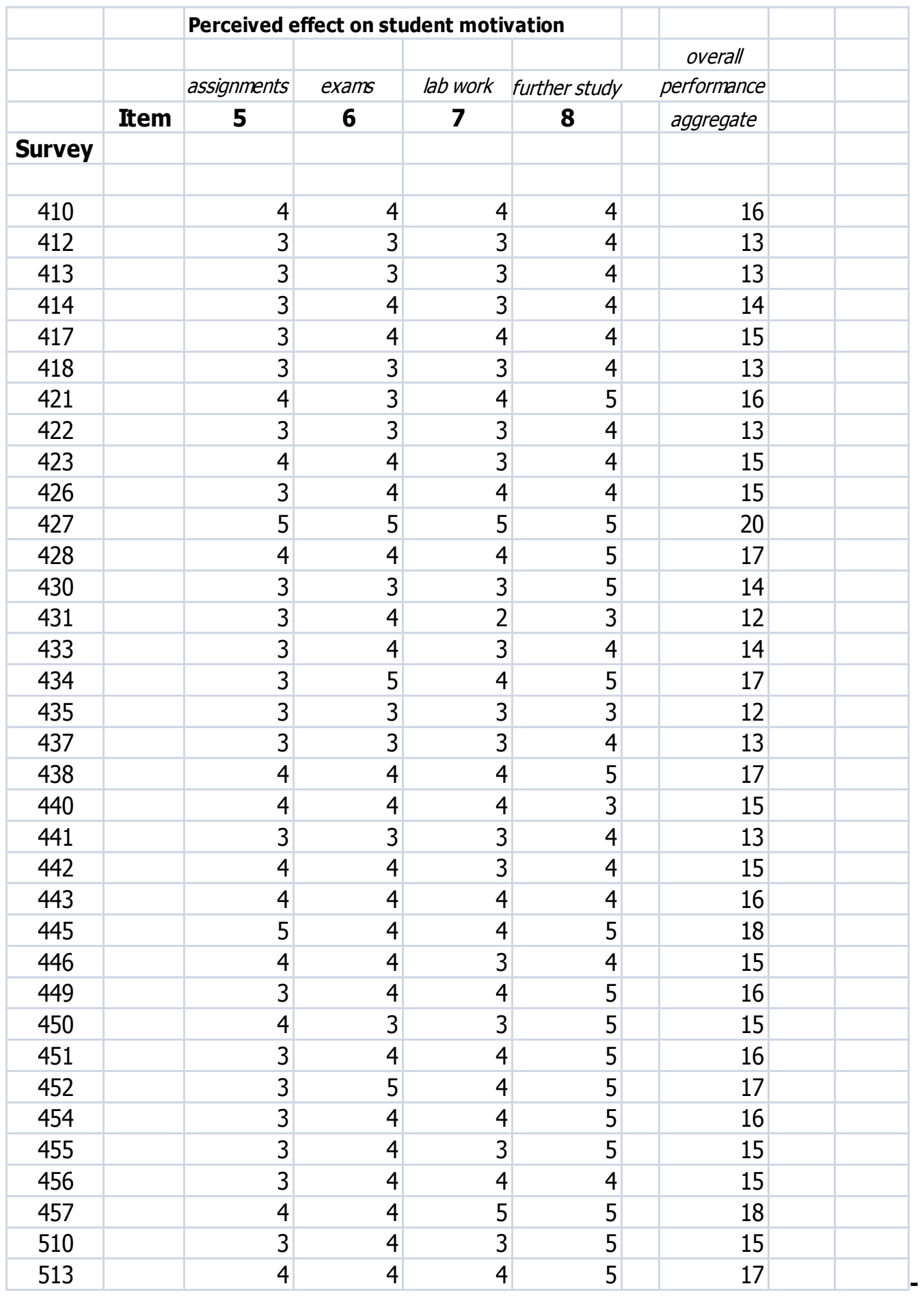




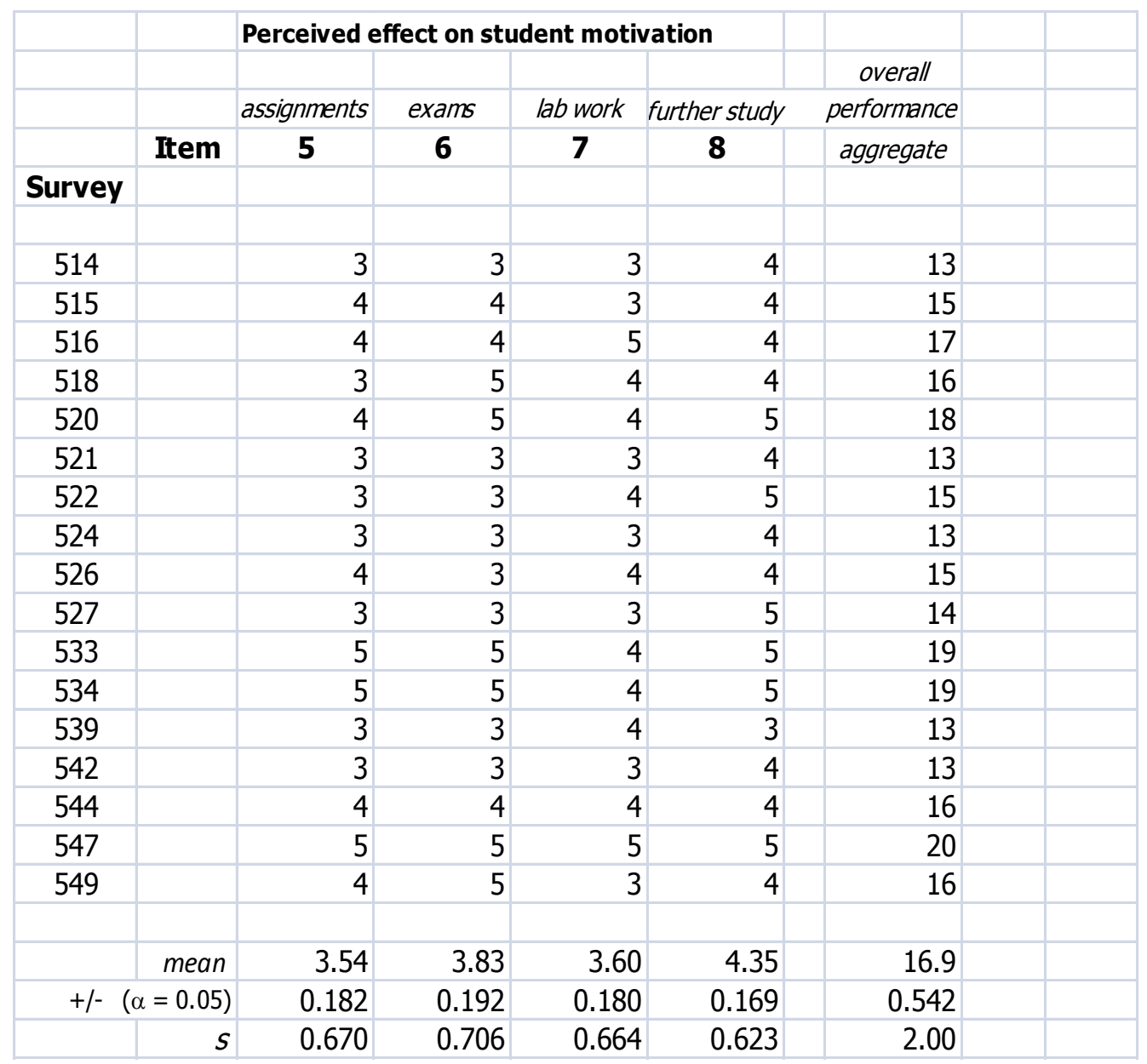




\begin{tabular}{|c|c|c|c|c|c|c|}
\hline & & & \multicolumn{2}{|c|}{ Additional survey responses } & & \\
\hline & & & & & & \\
\hline & & \multicolumn{2}{|c|}{ demonstrations per week } & planned & yrs teaching & yrs chemistry \\
\hline & & viewed & performed & demonstrations / week & experience & experience \\
\hline & Item & 9 & 10 & 11 & 12 & 13 \\
\hline \multicolumn{7}{|l|}{ Survey } \\
\hline & & & & & & \\
\hline 410 & & 0.5 & 3.5 & maintain & 13 & 11 \\
\hline 412 & & 0 & 3 & maintain & 26 & 23 \\
\hline 413 & & 1.5 & 2.5 & increase & 1 & 1 \\
\hline 414 & & 1 & 0.75 & increase & 3 & 3 \\
\hline 417 & & 0 & & increase & 5 & 5 \\
\hline 418 & & 1.5 & & maintain & 10 & 10 \\
\hline 421 & & 0.5 & 1 & increase & 18 & 18 \\
\hline 422 & & 0 & 0.33 & increase & 13 & 13 \\
\hline 423 & & 1.5 & 1.5 & increase & 42 & 42 \\
\hline 426 & & 0.1 & 0.25 & increase & 11 & 11 \\
\hline 427 & & 5 & 5 & maintain & 22 & 22 \\
\hline 428 & & 1.5 & 0.5 & increase & 7 & 7 \\
\hline 430 & & 1.5 & 1.5 & increase & 21 & 21 \\
\hline 431 & & 1 & 0.67 & increase & 10 & 10 \\
\hline 433 & & & 0.125 & increase & 9 & 9 \\
\hline 434 & & & 0.33 & maintain & 36 & 36 \\
\hline 435 & & 1 & 1 & increase & 10 & 2 \\
\hline 437 & & & & maintain/increase & 8 & 8 \\
\hline 438 & & 0 & 0.25 & increase & 21 & 4 \\
\hline 440 & & 2 & 0 & increase & 1 & 1 \\
\hline 441 & & 0 & 1.5 & maintain & 7 & 7 \\
\hline 442 & & 0.5 & 0.4 & maintain/increase & 4 & 4 \\
\hline 443 & & 1 & 1 & maintain & 9 & 9 \\
\hline 445 & & 1 & 1.5 & increase & 19 & 19 \\
\hline 446 & & 0.4 & & increase & 38 & 38 \\
\hline 449 & & 1 & 1.5 & maintain & 17 & 15 \\
\hline 450 & & 1.5 & 1 & increase & 1 & 1 \\
\hline 451 & & 2 & & maintain & 5 & 5 \\
\hline 452 & & 0.75 & 4 & maintain & 44 & 44 \\
\hline 454 & & 2 & 2.5 & maintain & 10 & 8 \\
\hline 455 & & 0 & 2 & maintain/increase & 19 & 19 \\
\hline 456 & & 1.5 & 1.5 & increase & 9 & 9 \\
\hline 457 & & 0 & 1.5 & maintain & 34 & 32 \\
\hline 510 & & 1 & 1 & increase & 1 & 1 \\
\hline 513 & & 1 & 1 & maintain & 10 & 7 \\
\hline
\end{tabular}




\begin{tabular}{|c|c|c|c|c|c|c|}
\hline & & & \multicolumn{2}{|c|}{ Additional survey responses } & & \\
\hline & & \multicolumn{2}{|c|}{ demonstrations per week } & planned & yrs teaching & veschemistry \\
\hline & & viewed & performed & demonstrations / week & experience & experience \\
\hline & Item & 9 & 10 & 11 & 12 & 13 \\
\hline \multicolumn{7}{|c|}{ Survey } \\
\hline 514 & & & 0.4 & maintain & 2 & 2 \\
\hline 515 & & 1.5 & 1.5 & increase & 11 & 11 \\
\hline 516 & & 1 & 1 & increase to three & 20 & 2 \\
\hline 518 & & 1.5 & 2.5 & maintain/increase & 11 & 11 \\
\hline 520 & & 0 & 0.5 & maintain/increase & 21 & 9 \\
\hline 521 & & 0 & 1 & maintain & 39 & 39 \\
\hline 522 & & & 1.5 & maintain/increase & 13 & 13 \\
\hline 524 & & 1.5 & 1.5 & increase to 2.5 & 20 & 20 \\
\hline 526 & & 1 & 0.5 & maintain & 26 & 20 \\
\hline 527 & & 0 & 1.5 & increase & 20 & 20 \\
\hline 533 & & 1 & 2 & maintain & 7 & 7 \\
\hline 534 & & 0 & 1 & increase & 17 & 17 \\
\hline 539 & & 0.5 & 0.5 & maintain & 25 & 15 \\
\hline 542 & & 1 & 2 & increase & 13 & 11 \\
\hline 544 & & 2.5 & 3 & maintain & 15 & 4 \\
\hline 547 & & 2 & 3 & maintain & 30 & 0 \\
\hline \multirow[t]{3}{*}{549} & & 0.05 & 0.25 & maintain & 5 & 5 \\
\hline & & & & & & \\
\hline & & & & mean & 15.6 & 13.1 \\
\hline
\end{tabular}




\section{Appendix H: Project Expenditures}

Cash incentives for survey participants:

99 @ \$5/completed survey: $\quad \$ 495.00$

Charitable Donations:

$\begin{array}{ll}62 @ \text { @ 10/survey: } & \$ 620.00 \\ 14 @ \$ 20 / \text { telephone or email interview: } & \$ 280.00\end{array}$

Supplies (stationery, postage, photocopies, approximate cost):

$\$ 200.00$

Total (approximate):

$\$ 1595.00$ 